\title{
Insights into membrane-bound presenilin 2 from all-atom molecular dynamics simulations
}

Dehury, Budheswar; Tang, Ning; Kepp, Kasper Planeta

Published in:

Journal of Biomolecular Structure and Dynamics

Link to article, DOI:

10.1080/07391102.2019.1655481

Publication date:

2020

Document Version

Peer reviewed version

Link back to DTU Orbit

Citation (APA):

Dehury, B., Tang, N., \& Kepp, K. P. (2020). Insights into membrane-bound presenilin 2 from all-atom molecular dynamics simulations. Journal of Biomolecular Structure and Dynamics, 38(11), 3196-3210.

https://doi.org/10.1080/07391102.2019.1655481

\section{General rights}

Copyright and moral rights for the publications made accessible in the public portal are retained by the authors and/or other copyright owners and it is a condition of accessing publications that users recognise and abide by the legal requirements associated with these rights.

- Users may download and print one copy of any publication from the public portal for the purpose of private study or research.

- You may not further distribute the material or use it for any profit-making activity or commercial gain

- You may freely distribute the URL identifying the publication in the public portal 


\section{Insights into membrane-bound presenilin 2 from all-atom molecular dynamics simulations}

\section{Budheswar Dehury, Ning Tang \& Kasper P. Kepp}

To cite this article: Budheswar Dehury, Ning Tang \& Kasper P. Kepp (2019): Insights into membrane-bound presenilin 2 from all-atom molecular dynamics simulations, Journal of Biomolecular Structure and Dynamics, DOI: 10.1080/07391102.2019.1655481

To link to this article: https://doi.org/10.1080/07391102.2019.1655481

Accepted author version posted online: 12 Aug 2019.

Submit your article to this journal ¿

III Article views: 11

View Crossmark data $\nearrow$ 


\section{Insights into membrane-bound presenilin 2 from all-atom molecular dynamics simulations}

Budheswar Dehury, Ning Tang, and Kasper P. Kepp*

DTU Chemistry, Technical University of Denmark, DK-2800 Kongens Lyngby, Denmark

*Corresponding author. E-mail: kpj@kemi.dtu.dk. Phone: +045 45252409

\section{Abstract}

Presenilin 1 and 2 (PS1 or PS2) are main genetic risk factors of familial Alzheimer's disease (AD) that produce the $\beta$-amyloid (A $\beta$ ) peptides and also have important stand-alone functions related to e.g. calcium signaling. Most work so far has focused on PS1, but humanans carry both PS1 and PS2, and mutations in both cause AD. Here, we develop a computational model of PS2 in the membrane to address the question how pathogenic PS2 mutations affect the membraneembedded protein. The models are based on cryo-electron microscopy structures of PS1 translated to PS2, augmented with missing residues and a complete all-atom membrane-water system, and equilibrated using three independent 500-ns simulations of molecular dynamics with a structure-balanced force field. We show that the 9-transmembrane channel structure is substantially controlled by major dynamics in the hydrophilic loop bridging TM6 and TM7, which functions as a "plug" in the PS2 membrane channel. TM2, TM6, TM7 and TM9 flexibility controls the size of this channel. We find that most pathogenic PS2 mutations significantly reduce stability relative to random mutations, using a statistical ANOVA test with all possible mutations in the affected sites as a control. The associated loss of compactness may also impair calcium affinity. Remarkably, similar properties of the open state are known impair the binding of substrates to $\gamma$-secretase, and we thus argue that the two mechanisms could be functionally related.

Keywords: Alzheimer's disease, presenilin 2, mutations, dynamics, membrane 


\section{Introduction}

Alzheimer's disease (AD) is the most common form of dementia affecting tens of millions with devastating effects on patients, families, communities, and healthcare systems.(Ballard et al., 2011; Nichols et al., 2019) AD is mostly occurring sporadically, modulated by many risk factors, but a small fraction of particularly severe, early-onset cases of familial AD (FAD) are caused by mutations in the genes coding for the amyloid precursor protein (APP) or the two similar proteins presenilins 1 and 2 (PS1 and PS2).(Levy-Lahad et al., 1995; Ryman et al., 2014) In neurons, APP is cleaved by $\alpha$ - or $\beta$-secretase resulting in APP-C83 or APP-99.(Bart De Strooper, Iwatsubo, \& Wolfe, 2012; Vassar et al., 1999) APP-C99 is then cleaved by the multi-subunit intramembrane aspartyl protease $\gamma$-secretase to produce the infamous $\beta$-amyloid peptides $(\mathrm{A} \beta)$ of different length, depending on the extent of C-terminal trimming.(Bolduc, Montagna, Seghers, Wolfe, \& Selkoe, 2016; B De Strooper et al., 1998; Takami et al., 2009; Tomita, 2014; Wolfe et al., 1999)

$\gamma$-secretase contains either PS1 or PS2 together with the other three subunits.(Holmes, Paturi, Selkoe, \& Wolfe, 2014; Knappenberger et al., 2004; T. Sato et al., 2007) The nine TM helices of PS1 form a porous structure where two catalytic aspartates are located within the convex side of the surface of TM6 and TM7.(Bolduc, Montagna, Seghers, et al., 2016; Bart De Strooper et al., 2012; Watanabe, Takagi, Tominaga, Tomita, \& Iwatsubo, 2010) Activation of the enzyme complex requires auto-proteolysis of the intracellular hydrophilic loop bridging TM6 and TM7 and leads to the formation of N-terminal (NTF, TMs 1-6) and C-terminal fragments (CTF, TMs 7-9).(Knappenberger et al., 2004; Tomita, 2014) The NTF and CTF harbor each one of the catalytic aspartates,(Wolfe et al., 1999) suggesting that their mutual distance and thus the size of the active site could vary to affect cleavage. FAD mutations may impair catalytic activity by changing the conformational interaction with $\gamma$-secretase substrates.(Chávez-Gutiérrez et al., 2012; Szaruga et al., 2017) 
Our previous computational studies of PS1 proteins in membranes have identified conformational changes in the catalytic pocket (open, semi-open and closed) with the open state causing weaker substrate binding and less retention time and trimming, and thus increased $\mathrm{A} \beta_{42} / \mathrm{A} \beta_{40}$ ratio, viz. the Fit-Stay-Trim (FIST) mechanism.(Somavarapu \& Kepp, 2016a, 2017; Tang, Somavarapu, \& Kepp, 2018) This terminology of open and closed states relates to the active site size, not the N-terminal-C-terminal donor-acceptor fluorophore distance obtained from FRET, which measures two different "open" (extended) and "closed" (compressed) states(Uemura et al., 2009; Wahlster et al., 2013). An increased $A \beta_{42} / A \beta_{40}$ ratio is the most consistent property of FAD-causing mutations in PS1(Kelleher \& Shen, 2017; Sun, Zhou, Yang, \& Shi, 2016) and PS2(Finckh et al., 2000; Levy-Lahad et al., 1995; Rogaev et al., 1995) mutations, and the ratio correlates with the onset of disease if one disregards the very distinct G384A mutation next to the catalytic aspartate that destroys activity completely.(Sun, Zhou, et al., 2016; Tang \& Kepp, 2018). Experimental and theoretical studies indicate that $\gamma$-secretase modulators cause allosteric changes in PS1 most likely favoring the semi-open active state, which increases the proteolytic cleavage of C99 and lowers the A $\beta 42 / 40$ ratio.(Raven et al., 2017; Tang et al., 2018).

The human PS proteins are highly homologous (63\% sequence identity) and are involved in various biological processes.(Contino et al., 2017; Filadi et al., 2016; Lai et al., 2003a; Lee et al., 1996) More than 200 FAD-associated mutations have been reported in PS1, and about 50 in PS2.(Ryman et al., 2014) PS2 mutations are less severe (clinical onset 15 years later on average), although specific activity is similar, perhaps because the two proteins are expressed differently and locate to different parts of the cell.(Filadi et al., 2016; Lai et al., 2003b) The role of PS1/PS2 has mostly been considered in the context of $\mathrm{A} \beta$ production in $\gamma$-secretase. However, PS1/PS2 are known to have functions on their own(Duggan \& McCarthy, 2016; Kelleher \& Shen, 2017; Saura et al., 2004; Tu et al., 2006; Zampese et al., 2011) and by far the largest cause of FAD is 
mutations in PS1 or PS2, not APP, and not the $\alpha$-secretases whose hypomorphic variants would be expected to increase A $\beta$ production substantially(Kepp, 2017; Shen \& Kelleher, 2007).

Considerations such as these have led to the proposal of a presenilin-alone hypothesis of AD.(Saura et al., 2004; Shen \& Kelleher, 2007; Walker, Martinez, Brunkan, \& Goate, 2005) It is of interest in this light to explore the role and impact of mutations on PS1/PS2 outside the $\gamma$ secretase context. Even if this hypothesis is not correct, we need to understand the PS-alone functions regardless of their pathogenic role.(Bart De Strooper, 2007) If these functions are impaired they could indirectly also affect the association of PS1/PS2 with $\gamma$-secretase leading to A $\beta$ production. Finally, the fact that humans use both PS1 and PS2 invites investigation, yet so far all experimental structural studies, all computational studies, and most cell biology studies have focused on PS1, sometimes alone but mostly in the context of $\gamma$-secretase.

The recent revolution in high-resolution cryogenic electron microscopy (cryo-EM) brings major new insights into the structure of membrane proteins, including $\gamma$-secretase.(Yang et al., 2019; Zhou et al., 2019) So far, eight cryo-EM structures of human PS1 $\gamma$-secretase (PDB ID: 4UIS, 5A63, 5FN2, 5FN3, 5FN4, 5FN5, ) have been solved at different resolution without the natural substrate(Bai, Yan, et al., 2015; Bai, Rajendra, Yang, Shi, \& Scheres, 2015; Lu et al., 2014; Sun et al., 2015) and with natural substrate (6IYC and 6IDF) forms.(Yang et al., 2019; Zhou et al., 2019) Of these, 5FN2 is complexed with an inhibitor (DAPT) and 5FN5 contains an unspecified helix fragment in the binding site. These structures have established the 9TM topology of PS1, the relative position of the four subunits, and also the disorder in some PS1 TMs presumably testifying to functionally important dynamics of PS1 helices TM2, TM3, TM6, and TM7. Recent structures of substrate-bound $\gamma$-secretase(Yang et al., 2019; Zhou et al., 2019) largely confirm previous computational and structural insights into the overall 9TM topology and the functional role of TM2 and TM6, which were proposed to act as gate doors for substrate entry and control substrate binding site compactness and cleavage.(Bai, Rajendra, et al., 2015; Somavarapu \& Kepp, 2016a, 2017) However, the new substrate-bound structures also reveal 
changes during substrate binding, most notably a loss of helicity in the substrate TM region and the formation of a substrate-PS1 $\beta$-sheet that may aid in protein-substrate recognition(Yang et al., 2019; Zhou et al., 2019).

There is no experimental structure of PS2. Even when it comes, molecular dynamics (MD) simulations provide important complementary details on the dynamics in more complete atomic settings at ambient temperature in the membrane. In this work, we were particularly interested in how the presence of the membrane modulates the cryo-EM data, how the structure and dynamics of PS2 compare to PS1, and whether the FAD-causing PS2 mutations can be mapped on a structure to hint at their possible mode of action outside $\gamma$-secretase. Our corresponding previous all-atom PS1 structure and dynamics in the explicit water-membrane models(Somavarapu \& Kepp, 2016b, 2017) produced the same 9TM topology and TM2/TM6 movements that have been confirmed experimentally(Bai, Yan, et al., 2015; Zhou et al., 2019), but also revealed the importance of auto-cleavage maturation in enabling the multistate nature of the protein and the ability of the large hydrophilic maturation loop (HL2) to change secondary structure to have both strand and helix segments of functional importance(Somavarapu \& Kepp, 2016b).

This study attempts to understand the PS2 mutations mapped onto a structural-dynamic context and provides insight into how PS2 mutations can cause AD by acting on PS2 alone in the membrane and changing its channel function; the properties that are pathogenic in this scenario (favoring the open conformation state) are interestingly similar to those that we think cause increased $A \beta_{42} / A \beta_{40}$ ratios when acting in the $\gamma$-secretase complex, implying that both mechanisms may be relevant to disease.

\section{Computational methods}

\section{Homology modeling of PS2}

Due to lack of an experimental structure of PS2, homology modeling was performed to build the starting protein structure used for MD simulation in the membrane. The sequence of PS2 was obtained from the UniProtKB database (accession number P49810). BLAST search revealed that 
PS2 shares $\sim 65 \%$ sequence identity (having a query coverage of $94 \%$ ) with the cryo-EM structures of human PS1 in $\gamma$-secretase (PDB codes: 5A63B and 5FN2B)(Bai, Yan, et al., 2015; Bai, Rajendra, et al., 2015). 5A63 lacks the TM2 region, and both structures also lack the initial N-terminal region and the major hydrophilic maturation loop 2 (HL2) bridging the TM6 and TM7, which is cleaved in active $\gamma$-secretase. Thus to avoid any missing parts in our PS2 model, we combined the two structures with our previously developed MD-equilibrated complete model of PS1(Somavarapu \& Kepp, 2016b, 2017) as templates using Modeller version 9.20.(Webb \& Sali, 2017). It is noteworthy to mention that the large HL2 of PS 2 found to be smaller than PS1, which also harbors helix and $\beta$-strands in these region like the new cryo-EM structures (PDB: 6IYC and 6IDF). The PS2 structure covering Glu-77 to Ile-448 was modeled and refined using the loop-refinement protocol in Modeller. Based on the discrete optimized protein energy (DOPE) scoring function, the best model was selected for further loop and side chain optimization using Galaxy Refine(Heo, Park, \& Seok, 2013) and the What-IF(Hekkelman et al., 2010) tools, producing a final PS2 homology model. Because we were interested in the PS2 alone in the membrane, we studied the protein with intact HL2 (immature state), whereas the protein is mature auto-cleaved in the $\gamma$-secretase complex.

The optimized homology model was subjected to stereo-chemical quality control using SAVES version 5.0. The overall quality and energy profile of the PS2 model was assessed using ProSA-Web,(Wiederstein \& Sippl, 2007) as well as ProQ(Wallner \& Elofsson, 2003) and MolProbity.(Chen et al., 2010) To ensure that all essential details of our model respect the experimental structural data, we computed the root mean square deviation (RMSD) between the corresponding $\mathrm{C}_{\alpha}$ atom pairs of our model and the experimental cryo-EM structures 5FN2 and 5A63, using PyMOL.

\section{All-atom MD simulations of PS2 in a lipid bilayer}

The initial orientation of PS2 within the membrane was generated using the PPM server.(M. A. Lomize, Pogozheva, Joo, Mosberg, \& Lomize, 2012) The membrane-oriented PS2 model was 
embedded in a homogeneous POPC lipid bilayer using the CHARMM-GUI.(Jo, Kim, Iyer, \& Im, 2008) The obtained protein-membrane system includes 189 POPC lipid molecules and 15,530 TIP3P water molecules in a rectangular box size of $90 \AA \times 90 \AA \times 90 \AA$. NaCl was added to neutralize the system and additionally to reach a final, physiologically relevant ion concentration of $0.15 \mathrm{~mol} / \mathrm{L}$, since salt presence may affect protein structure and dynamics.(Y. Zhang \& Cremer, 2006) We used the structure-balanced CHARMM36m force field specifically developed to handle conformational changes in proteins.(Huang et al., 2016) The model was equilibrated using the typical six-step CHARMM-GUI protocol. After the equilibration, 500-ns production runs were carried out using GROMACS (version 2018.2, gpu version)(Abraham et al., 2015) with a 2-femtosecond time step using LINCS algorithm for hydrogen bonds. The van der Waals and electrostatic interactions were computed using a Verlet switching function over the cutoff range 10-12 $\AA$, chosen large because of the known long-range correlations in PS1 and thus presumably also in PS2(Somavarapu \& Kepp, 2016b). During the equilibration and production phases, semi-isotropic pressure coupling was applied to keep the lipid bilayer in the lamellar phase. The Berendsen thermostat(Berendsen, Postma, van Gunsteren, DiNola, \& Haak, 1984) was used during equilibration and the Nose-Hoover thermostat was used for the production runs(Martyna, Klein, \& Tuckerman, 1992) at 303.15 K. The Parrinello-Rahman barostat(Parrinello \& Rahman, 1981) was used for production phases in order to keep the pressure at 1 bar.

To account for variations due to ensemble sampling, we performed the study in triplicate, using three statistically independent (with randomly seeded velocities) simulations of $500 \mathrm{~ns}$ each for a total of $1.5 \mu$ s of simulation time. It should be noted that other studies have used shorter or longer simulation times, but the longer are based on coarse-grained methods that do not capture the atomic membrane-protein-water dynamics, which are hydrogen-bond dominated. The timescale of the functionally relevant helix tilts are less than $100 \mathrm{~ns}$ as they occur multiple times on this time scale and produce well sampled distributions if they are flexible(Somavarapu 
\& Kepp, 2017), in accordance with the typical timescale of such movements,(Adcock \& McCammon, 2006) and that equilibrated ensembles are reached after 100-200 ns. These tilts are the relevant properties because they control the catalytic pocket size.(Somavarapu \& Kepp, 2016b) Thus, the emphasis of computer time use should be on more realistic atomic models as used here (complete all-atom membrane-water-protein systems with hydrogens present). The NTF and CTF loop fragments equilibrate on the same time scale. The slowest motions occur in the nicastrin extracellular domain and requires $~ 100 \mathrm{~ns}$ of simulation with several breathing modes typically seen during simulation(Somavarapu \& Kepp, 2017) consistent with experimentally known dynamics of this extracellular domain.(Bolduc, Montagna, Gu, Selkoe, \& Wolfe, 2016; Shah et al., 2005)

\section{Trajectory and principal component analysis}

To investigate system stability, the backbone RMSD, the radius of gyration $\left(\mathrm{R}_{\mathrm{g}}\right)$, solvent accessible surface area (SASA) and the $\mathrm{C}_{\alpha}$-root-mean-square fluctuation (RMSF) were calculated using the standard GROMACS built-in tools. Distance profiles and properties of TM helices were calculated with the specific modules of GROMACS. Secondary structure during the course of simulation was assessed with the timeline viewer of VMD.(Humphrey, Dalke, \& Schulten, 1996)

The gmx covar and gmx anaeig utility tools were used to perform the principal component analysis (PCA) to explore the dynamic ensemble of PS2. To understand the global motions of PS2 within the membrane, porcupine plots were generated using PC1 and PC2 via the modevector.py script. Free energy landscape (FEL) analysis was conducted to pinpoint the dominant conformation states of the protein-membrane system the using gmx sham module of GROMACS. In order to characterize the distinct states of the ensemble in a simple way, the most representative structure of PS2 from cluster analysis was obtained for all three simulations using the gmx cluster tool with the equilibrated last $300 \mathrm{~ns}$ of the trajectories as input, using a cut-off 
of $0.2 \mathrm{~nm}$.(Daura et al., 1999) The images were rendered using BIOVIA DS Visualizer and PyMOL.

\section{Acquisition of mutation data of PS2 associated with FAD}

Data on mutations of PS2 linked with FAD were collected from The Alzheimer Disease \& Frontotemporal Dementia Mutation Database (http://www.molgen.ua.ac.be/ADmutations/) and the database of Alzforum (https://www.alzforum.org/mutations). Our analysis primarily focused on the effect of single-residue substitutions on our complete equilibrated PS2 structure, with a total of 46 single-residue non-synonymous substitutions identified.

\section{Annotation of mutational data of PS2}

The possible mutational effects were investigated by using our equilibrated all-atom structures of PS2 as input to several structure-based mutation analysis tools, I-Mutant3.0,(Capriotti, Fariselli, \& Casadio, 2005) SDM2.0,(Pandurangan, Ochoa-Montaño, Ascher, \& Blundell, 2017) mCSM,(D E Pires, Ascher, \& Blundell, 2013) DUET,(Douglas E V Pires, Ascher, \& Blundell, 2014) DynaMut,(Rodrigues, Pires, \& Ascher, 2018) and MaestroWeb(Laimer, Hofer, Fritz, Wegenkittl, \& Lackner, 2015), in all cases using default settings. After computing the effect of mutation, the dataset was divided into two sets: clinically confirmed pathogenic and nonpathogenic mutations. To enable a control group for the properties of the pathogenic mutations, we also performed site-specific computational saturation mutagenesis for all sites with reported confirmed pathogenic mutants, and compiled the properties of these amino acid changes in 13 sites. To estimate the impact of mutation, we used I-Mutant3.0(Capriotti et al., 2005; Capriotti, Fariselli, Rossi, \& Casadio, 2008), SDM(Pandurangan et al., 2017; Worth, Preissner, \& Blundell, 2011), mCSM(D E Pires et al., 2013), and DUET(Douglas E V Pires et al., 2014). The analysis of variance (ANOVA) was conducted to establish statistically significant differences between the means of pathogenic (15), non-pathogenic (9) and all other mutations in the affected sites (232 mutations). 


\section{Results and discussion}

\section{Nine TM architecture of PS2 within a membrane}

Using available homologous cryo-EM structures (5FN2 and 5A63) of PS1 as templates, we constructed the human PS2 model shown in Figure 1A. The structural superimposition of our proposed PS2 model with 5FN2, 5A63, and our previously reported all-atom PS1 homology model(Somavarapu \& Kepp, 2016b) displayed $\mathrm{C}_{\alpha}$-RMSD values of $0.77 \AA$, $0.78 \AA$ and $0.23 \AA$, respectively. The superposition in Figure S1 shows that our proposed PS2 structure fully respects the constraints from experimental PS1 structures. A close fit is seen with the experimental structures in TM helices and in HL1. However, a notable difference between the PS1 and PS2 structures is seen in the topological arrangement of HL2, where two $\beta$-strands occur together with a large helix anchoring this loop (Figure 1A). Interestingly, the length of each TM differs somewhat in PS1 and PS2. The C-terminal end and the N-terminal end of TM3 vary somewhat before MD simulation in the membrane (Figure S1). Also, TM9 adopted an extended helix conformation indicating its potential plasticity, consistent with its possible role as gatekeeper for substrate binding.(C. Sato, Takagi, Tomita, \& Iwatsubo, 2008; Tolia, Horré, \& De Strooper, 2008) The side chains of the catalytic Asp-263 and Asp-366 are consistent with those in cryo-EM structure of PS1(Bai, Yan, et al., 2015) with their mutual $\mathrm{C}_{\alpha}$-distance being $10.2 \AA$ ( 10.6 $\AA$ for 5A63). The stereo-chemical quality of the model assessed through Procheck(Laskowski, MacArthur, Moss, Thornton, \& IUCr, 1993) had 90.5\% residues in the most allowed regions, $8.3 \%$ in the allowed regions, $0.3 \%$ in additionally allowed regions and 0.9\% (only three residues: Lys-146, Glu-280, and Asp-308) in the disallowed region as indicated by the corresponding Ramachandran plot. Similarly, the overall quality scores obtained from ERRAT(Colovos \& Yeates, 1993) and Verify 3D indicate that the modeled structure is realistic and a good starting point for MD simulation. 
A

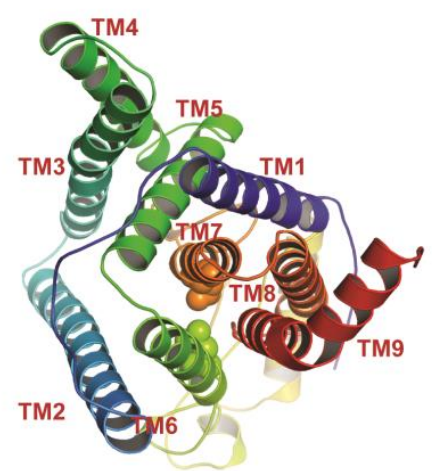

C

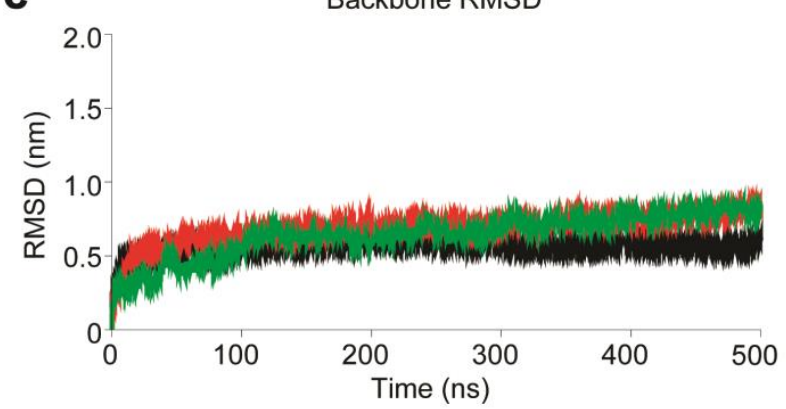

B

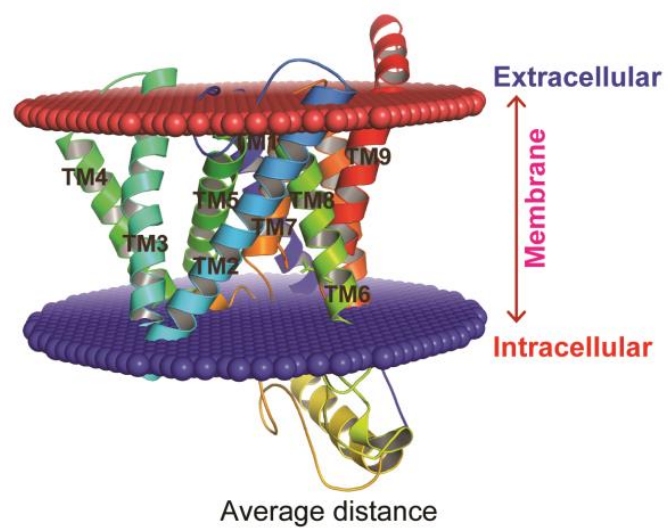

D

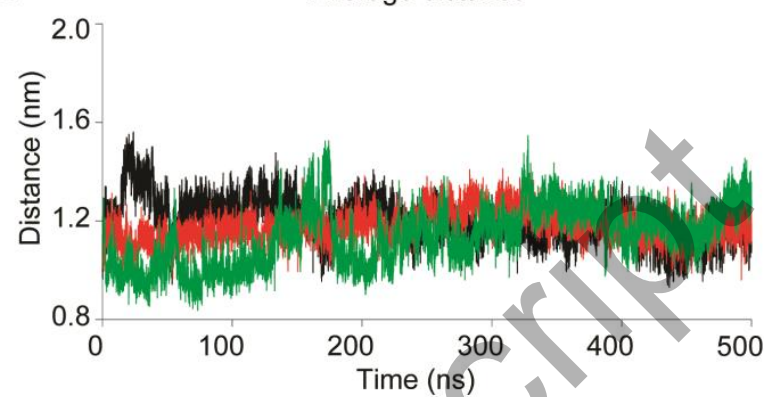

E

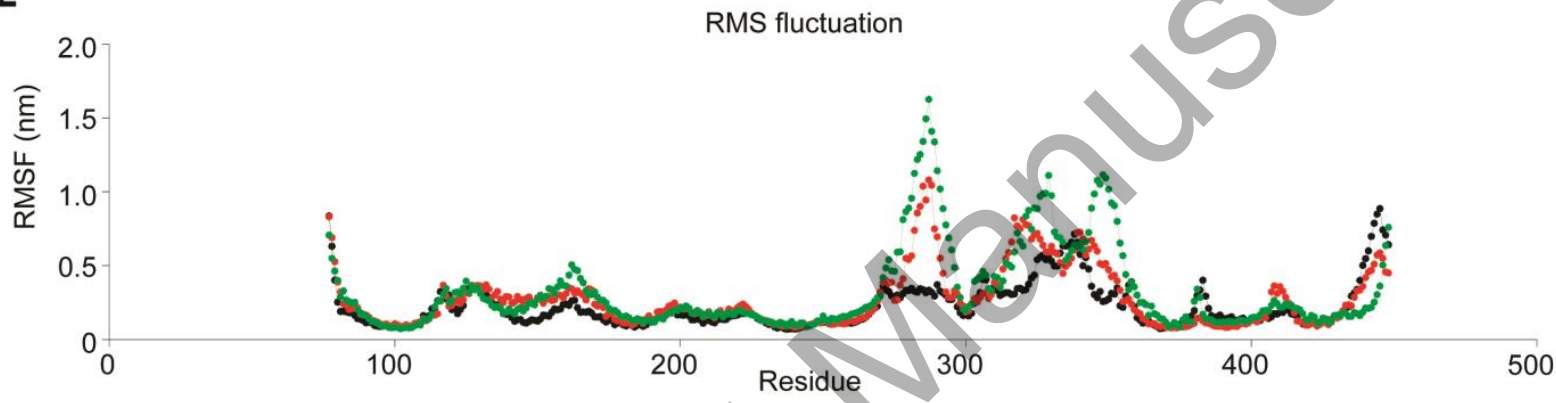

Figure 1. (A) The complete 9TM architecture of the homology modeled PS2 based on the cryoEM structures of PS1 (PDB ID: 5A63, 5FN3) and a previous complete homology model of PS1. The catalytic Asp-263 (TM6) and Asp-366 (TM7) are displayed in spheres. (B) The membranealigned view of the PS2 homology model. (C) Backbone RMSD of the complete PS2membrane-water system during three independent 500-ns MD simulations. (D) The distance between C $\alpha$ atoms of Asp-263 and Asp-366 of PS2 during the simulations. (E) The Ca-RMSF profile of each amino acid of PS2 during simulation in the lipid bilayer system (black: system 1, red: system 2 and green: system 3). 


\section{Quality control of the equilibrated membrane-protein system}

Prior to MD simulation, the PS2 model was membrane aligned as displayed in Figure $\mathbf{1 B}$ and embedded in homogenous lipid bilayer. PS2 is an evolved membrane protein functioning either alone or inside $\gamma$-secretase in membranes, and thus the dynamics of the surrounding lipid bilayer and its crosstalk with the protein is of interest. Membrane proteins adopt distinct conformational ensembles in membranes and the protein interaction with the phospholipids can contribute essentially to protein activity.(Zhuang, Dávila-Contreras, Beaven, Im, \& Klauda, 2016; Zhuang, Makover, Im, \& Klauda, 2014) Specifically, the PS1/PS2-alone functions center on membrane channel properties of the proteins which require an understanding of the protein in the actual membrane context.

The dynamic stability was investigated by monitoring backbone RMSD relative to the reference structure over the $500 \mathrm{~ns}$ of MD as displayed in Figure 1C. The three systems reach stable conformational ensembles after 100-150 ns, consistent with expectation from related systems;(Somavarapu \& Kepp, 2016b, 2017) this justifies the collection of statistics for the last $300 \mathrm{~ns}$ of each trajectory. The systems at equilibrium displayed average RMSD of $\sim 0.6 \mathrm{~nm}$. The catalytically relevant distance between the C $\alpha$ atoms of Asp-263 and Asp-366 are summarized in

Figure 1D; the distance may affect substrate cleavage.(Sun, Li, \& Shi, 2016) It varies between 10-13 $\AA$, with a small population of loose states where the distance reaches $15 \AA$. This dynamic variation implies both compact and loose active-site conformations, consistent with previous findings for PS1.(Somavarapu \& Kepp, 2017) We suggest that the flexibility enables water to enter the active site as required for proteolysis. The helix-flanked pore topology with variable interior space resembles two states of a membrane channel, with indications of both a closed and an open structure. The root-mean-square fluctuations of all atoms of PS2 averaged over the trajectories are shown in Figure 1E. In all systems, the TMs displayed least fluctuation whereas 
the loops HL1 and HL2 displayed substantial atomic motions ranging from 0.5 to $1.5 \mathrm{~nm}$; similar loop movements have been observed previously for PS1.(Somavarapu \& Kepp, 2016b)

In order to ensure that our protein-membrane system is realistic, we compared our simulated bilayers to data from X-ray and NMR experiments, considering temporal and spatial averages of deuterium order parameters, the local density of the membranes, the bilayer thickness, and the area per lipid (Tables S1-S3). The averaged parameters are in excellent agreement with typical experimental values for bilayer structures (Figure 2A-2F). The deuterium order parameters and the splitting of values near the lipid head-group closely resemble experimental values (Figure 2A,2C,2E).(Zhuang et al., 2016) The density profiles of the different groups of lipids are strong indicators of membrane structural changes. The local density of the head-group, tail-group, and phosphate across the full lipid bilayer were all close to experimental values expected for the bilayer system and similar for all three simulations (Figure 2B,2D,2F). Finally, the lipid per unit area of $\sim 0.63$ resembles that obtained from other CHARMM36 simulations and experiments (Figure 2G,2H,2I).(Lyubartsev \& Rabinovich, 2016) The quality control of PS2-membrane system is important because the membrane affect protein function. Notably, thinner membranes most likely favor $\mathrm{A} \beta_{42}$ production.(Holmes, Paturi, Ye, Wolfe, \& Selkoe, 2012) This is in excellent agreement with the FIST model(Somavarapu \& Kepp, 2017; Tang et al., 2018) because thinner membranes typically pack the protein less well. Relevant variations in the local membrane thickness (Figure 2G, 2H, 2I) occur in our simulations that enable crosstalk to protein conformations, to be discussed below.

The lipid headgroups and membrane thickness are can influence the structure and activity of membrane proteins(A. L. Lomize, Pogozheva, Lomize, \& Mosberg, 2006). In $\gamma$-secretase, the lipid composition affects the biological activity of PS1(Holmes et al., 2012). A membrane composed solely of phosphatidylcholine lipids retains full activity of $\gamma$-secretase; however, other homogeneous membranes reduce cleavage activity. In our simulations of PS2, we observe changes in the tilt angles of TMs (most importantly TM2, TM3, TM7 and TM9) that correlate 
with variations in membrane thickness (Figure S2), and the membrane thickness affects the position of the catalytic aspartates within the POPC lipid bilayer (Figure S3).
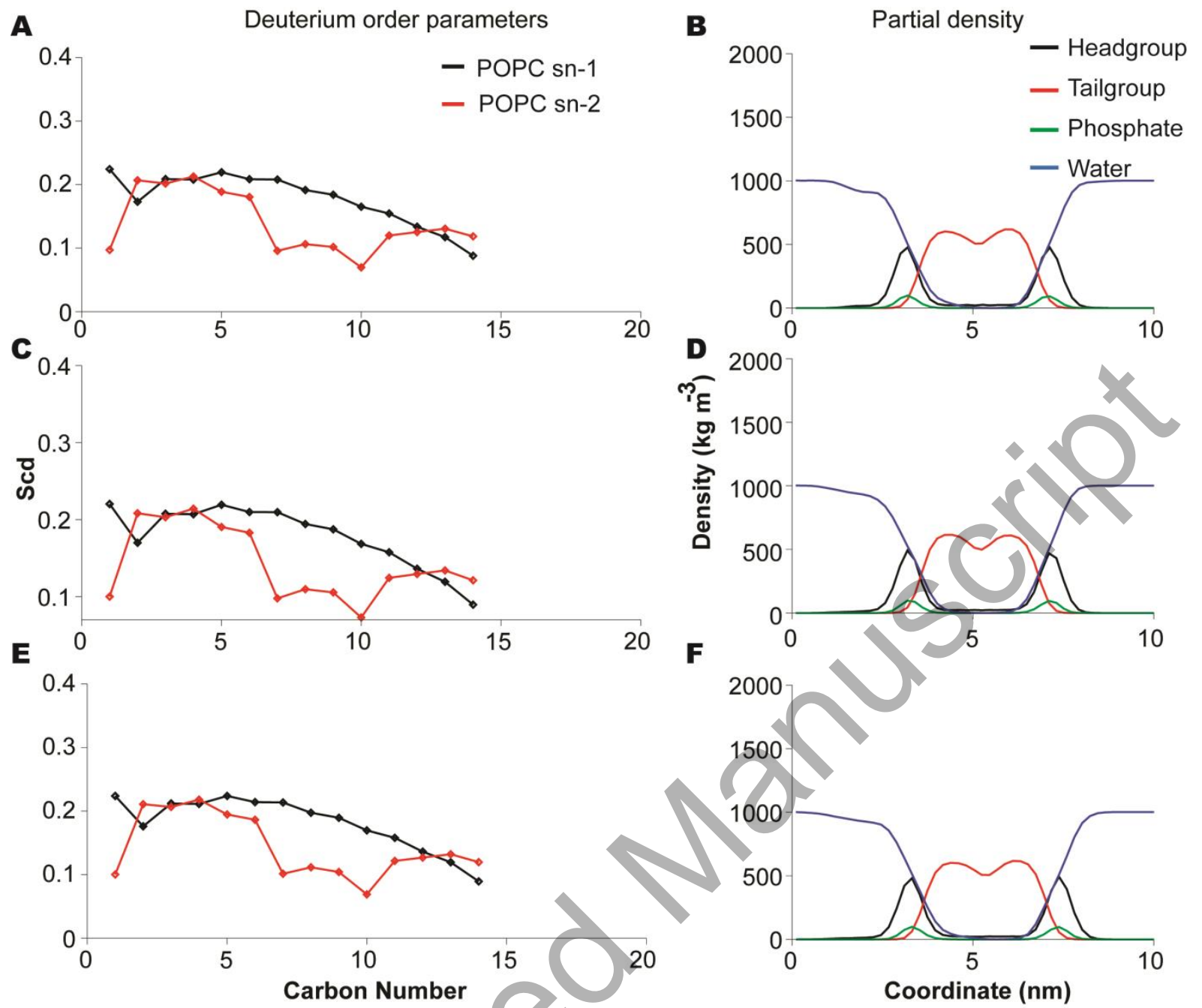

G
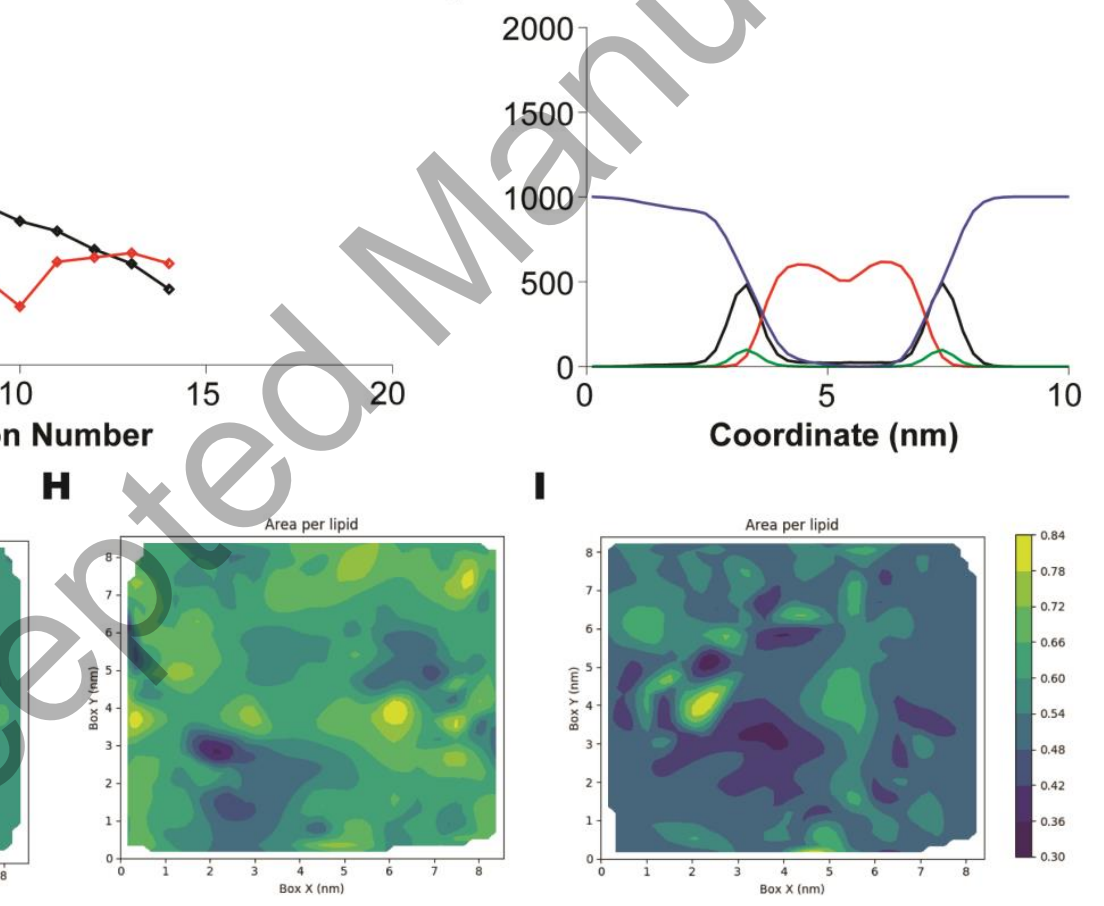

I
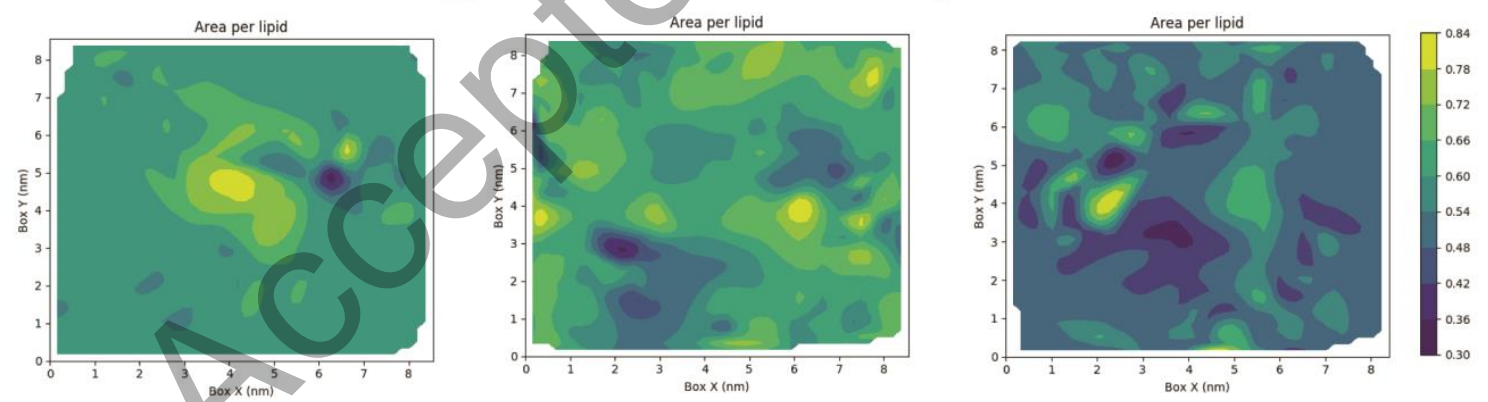

Figure 2. Properties of POPC lipid bilayer viz. lipid order parameter, density of the membrane, and area per lipid profile during the 500-ns MD simulation. The figure shows the deuterium order parameters of the POPC membrane (A: System 1, C: System 2 and E: System 3), the density profiles of lipid head groups, tail groups, phosphate, and water (B: System 1, D: System 
2 and F: System 3), and the average area per lipid of each system in the lipid bilayer (G: System 1, H: System 2 and I: System 3).

\section{Prominent conformation states and channel morphology of PS2}

The major conformations of PS2 within the membrane were analyzed using PCA of the last 300 ns of each system. Figure S4A shows the eigenvalues of first two eigenvectors and the projection of the movements of main-chain atoms over the phase space. Figure S4B shows eigenvectors 1 and 2 plotted against each other. For a globular protein, the PS2 is distinctly variable in its conformational space, in agreement with the RMSF analysis. Replicate 1 (black) represents a more compact conformational ensemble, with Replicate 2 (red) being similar in structure but with slightly more variation. In contrast, Replicate 3 represents the most variable ensemble as displayed by PCA. Importantly, this variation is in line with a more variable active site space of PS2 (Figure 1D), suggesting that Replicate 3 represents a distinct open state.

In order to understand the global ensembles in detail, porcupine plots depicting the major movements were produced as shown in Figure 3. Figure 3A-C show the major movements according to eigenvector 1 of the PCA for the three simulations, whereas Figure 3D-F show the same movements for eigenvector 2, with longer cones representing larger movements. Consistent with the RMSF analysis, most TMs are rigid whereas HL1 and HL2 display important bending motions. However, an unusual and very significant motion is evident in the C-terminal of TM2 displaying an outward-inwards movement relative to the center of the protein, particularly evident in Figure 3C, 3E, and 3F. TM2 is known to be disordered in some PS1- $\gamma$-secretase cryoEM structures,(Bai, Yan, et al., 2015; Bai, Rajendra, et al., 2015) probably because of similar movements in PS1 as we identify for PS2 (the cryo-EM show an average electron density map with disorder and does not reveal the motion obtained here from MD). Similar TM2 movements where seen in the ensemble of PS1(Somavarapu \& Kepp, 2016b). Immature PS2 has less movement of TM6 than immature PS1. In contrast, PS2 displays very large movements in the 
CTF and in particular TM9 (Figure 3). PS2 has a much smaller HL2 than PS1 by $\sim 25$ residues to sequence gaps relative to PS1 in this area, and this shorter loop probably forces stronger inmembrane movements of the CTF. The conserved PAL motif adjacent to TM9 is critical for the catalytic activity of $\gamma$-secretase and the extended helical segment of TM9 greatly affects the outer part of the channel.

Although disputed,(Shilling, Mak, Kang, \& Foskett, 2012) many studies suggest that PS1/PS2 modify calcium homeostasis(Begley, Duan, Chan, Duff, \& Mattson, 1999; Brunello et al., 2009; Das, Tchedre, \& Mueller, 2012; LaFerla, 2002; Leissring et al., 2000; Nelson et al., 2011; Tu et al., 2006; Zatti et al., 2006; H. Zhang, Sun, Herreman, De Strooper, \& Bezprozvanny, 2010), perhaps by acting as calcium leak channels,(Guo et al., 1996; Honarnejad \& Herms, 2012; LaFerla, 2002; Saura et al., 2004; Tu et al., 2006), which is notable since calcium dyshomeostasis is a hallmark of AD.(Guo et al., 1996; Khachaturian, 1987; Mattson, 2010) Calcium transport is very structure, $\mathrm{pH}-$ and context dependent, which perhaps partly explains why results can differ between studies(Shilling et al., 2012). Calcium leak activity of cysteine point mutations indicate that TM7 and TM9 are important for calcium transport(Nelson et al., 2011). A recent study suggests that PS2 but not PS1 causes calcium leakage, which may reconcile the disagreement (Greotti et al., 2019).

PS2 has a notable channel morphology with the pore surrounded primarily by TM2, TM3, TM5, TM6, and TM7, with TM1, TM4, TM8, and TM9 constituting the outside flanking of this pore (Figure S5). This topology is in good agreement with the structure of the PS1 homolog from 2013 discovering such pore structure.(Li et al., 2013) However, in the 2013 structure, TM6 was not part of the pore, because the whole topology was looser. Since the structural homology is very high for the two proteins, the presence of the membrane in our structure rather than the crystal environment of the experimental PS1 homolog most likely enforces the more compact PS2 (Figure S5). Movements in HL1, TM2, TM9, and the PALP motif change the size of the pore and directly affect water accessibility and thereby, we presume, the dehydration and affinity 
of ions such as calcium within the PS2 channel, as summarized in Figure S6-S8. Since this pore size also affects the Asp-Asp distance we predict the two features to potentially be related in a biological function.

\section{Conformational states of PS2}

To further understand the TM topology, the two most representative snapshot structures obtained from cluster analysis of the equilibrated trajectories (200-500 ns) are shown in Figure 4A-4C. These structures superimpose well with the original homology model of PS2, which is very similar to the experimental PS1 structure without membrane (Figure S5), but show increased compactness of the pore due to TM2 and TM9 inward movements once the membrane is present. TM9 directly controls how flanked the channel is within the membrane consistent with its known dynamic features(Kong, Chang, Xia, \& Wong, 2015; Somavarapu \& Kepp, 2016b) (Figure S5B). Figure 4D-4F displays the free energy landscapes of PS2 with dark color indicating lower energy and more conformation sampling. Replicate 3 displays two low-energy basins whereas replicate 1 and 2 has a broader, more typical one-state protein basin. The first two are similar to those seen for immature PS1, and they differ markedly from the multistate landscapes caused by HL2 auto-proteolysis, which produces the NTF and CTF.(Somavarapu \& Kepp, 2016b) 

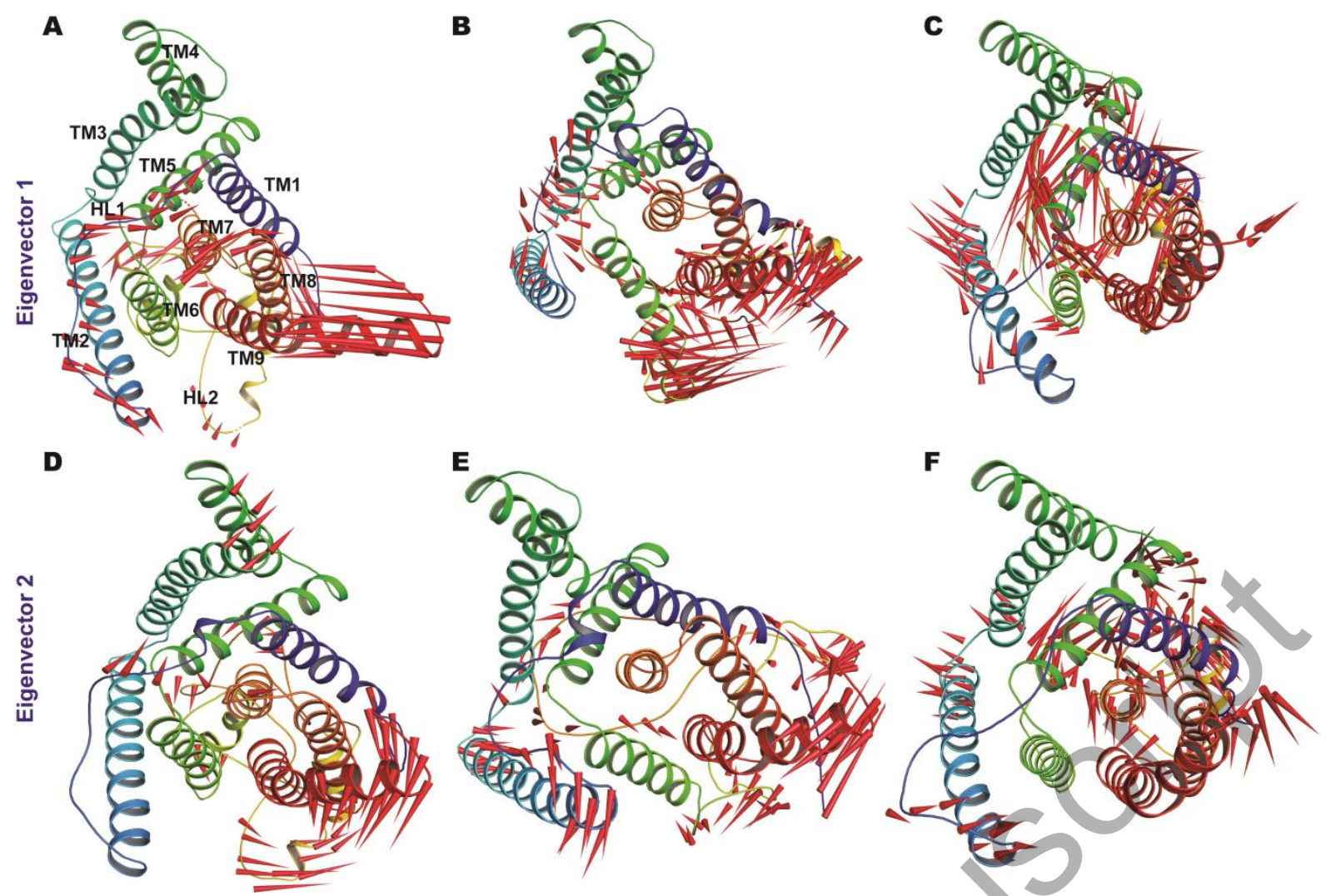

Figure 3. Porcupine plots displaying the dominant motions (eigenvectors EV1 and EV2) from principal component analysis of PS2 using the last $300 \mathrm{~ns}$ of three independent MD simulations. (A) The movement of EV1 of system 1. (B) The movement EV1 of system 2. (C) The movement EV1 of system 3. (D) The movement of EV2 of system 1. (E) The movement EV2 of system 2. (F) The movement EV2 of system 3. The cone sizes represent the strength of the movement. The most prominent changes are in HL1 and HL2, TM2, and TM9. 

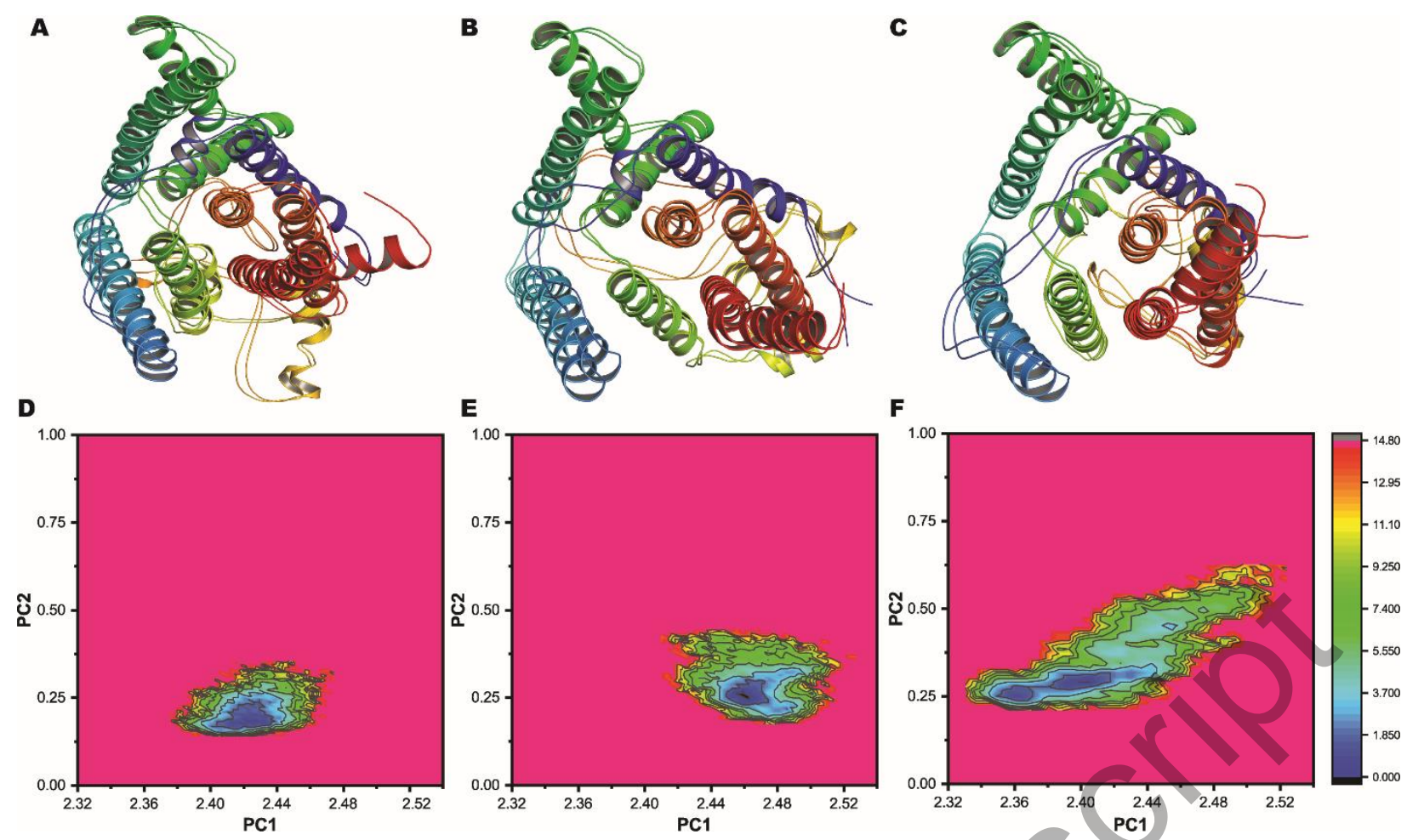

Figure 4. Superimposed views of two representative structures of PS 2 from the three different simulations in the POPC lipid bilayer. (A) Pair-wise structural superposition of the two most representative structures of PS2 from simulation 1. (B) Superposition of the two most representative structures from simulation 2. (C) Superposition of the two most representative structures from simulation 3. (D) The free energy landscape as a function of PC1 and PC2 for simulation 1. (E) Same as (D) for simulation 2. (F) Same as (D) for simulation 3.

To understand the helical structural changes in more detail, we extracted snapshots at a difference of 100 ns as shown in Figure $\mathbf{S 9}$ showing the overall changes in secondary structure at different times. Most TMs retained their helical properties; however one residue in TM9 changed to coil in simulations 2 and 3. Notably, the large HL2 where maturation occurs features a substantial helix segment which is unusual for a loop and has not been observed experimentally. However, this result is fully consistent with previous MD simulations of PS1 and various NMR data that support a helix segment in HL2.(Knappenberger et al., 2004) Furthermore, our finding of a moderately stable structural helix segment in HL2 immediately 
suggests that this part of the protein, which is cleaved by the enzyme itself in mature $\gamma$-secretase, is inherently helical once being cleaved, as is the case also for other TM substrates of $\gamma$-secretase. From this finding, we predict that the HL2 loop can enter the catalytic site in the protease complex in the identified helix form and thus undergo auto-cleavage to produce the NTF and CTF similar to that of other substrates. If the active site is occupied or too compact, or if HL2 is prevented from bending into the active site, such maturation will not occur. Interestingly, we observed major structural transitions in the auto-proteolysis loop HL2 from strand to turn/coil and coil to strand in two replicates, testifying to substantial structural plasticity of this loop (Figure S9 and S10). Recent cryo-EM studies have shown the importance of minor $\beta$-strandforming regions in defining substrate recognition.(Yang et al., 2019; Zhou et al., 2019)

The RMSD of the TM helices were computed as shown in Figure 5A. The helices are very stable except TM2, TM6, and TM9, consistent with the general analysis above. The looser state of replicate 3 (green) is largely due to changes in these helices, notably TM2. The persistence of each TM helix is shown in Figure 5B. We observed loss of helicity in TM9 suggesting that this helix is effectively two helices separated by a kink. This kink is not seen in the experimental 2013 structure(Li et al., 2013) but it features in the 2015 cryo-EM structure of the PS1- $\gamma$ secretase complex and is embedded in APH1-A.(Bai, Yan, et al., 2015) As seen from Figure S5, the kink is inwards and dynamic such that it opens and closes access to the pore of PS2. Cysteine-scanning mutagenesis(C. Sato et al., 2008; Tolia et al., 2008; J. Wang et al., 2006) and recent structural studies of PS1(Yang et al., 2019; Zhou et al., 2019) show the role of TM9 and the C-terminal PALP motif in the catalytic pore and in guiding substrates to the catalytic site. Leu-416 of the PALP motif forms contacts with residues from TM6, TM8, and TM9. Upon rearrangement of TM9 and the PALP motif, we observed that the cytoplasmic side of TM6 moved toward TM9, leading to a gate-opening movement involving TM2, TM9, and TM6, consistent with their larger RMSD (Figure 5A). The catalytic Asp-366 is partially exposed in the more open conformation enabling access of water as required for catalysis in the enzyme 
complex. In PS2, it resembles a more open channel structure that is more solvent-accessible and is suggested to have lower affinity for calcium.

A
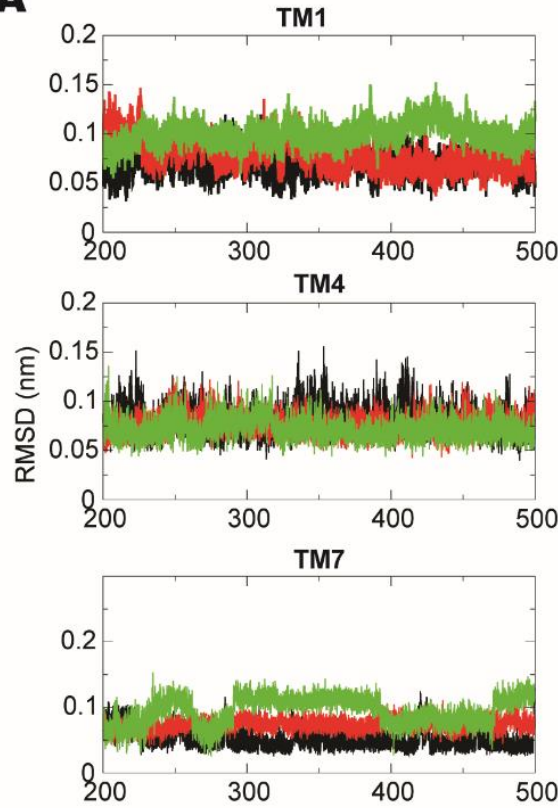

B
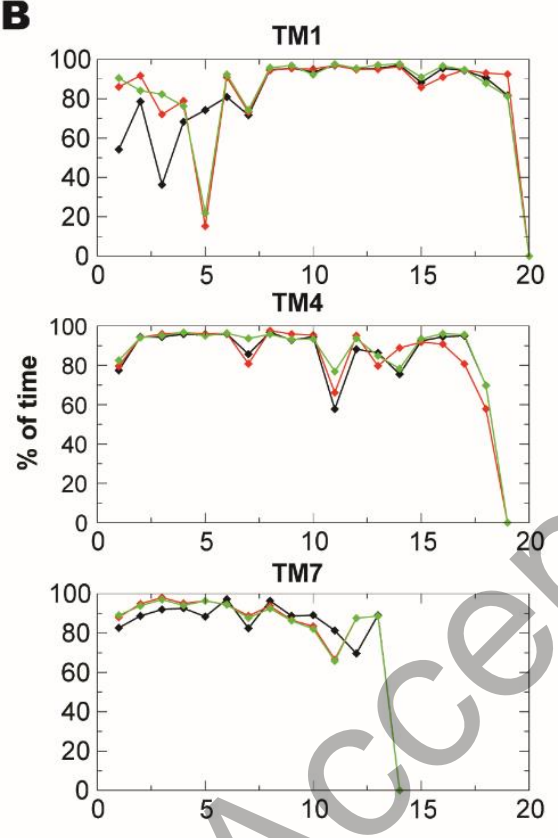

Backbone RMSD TM2
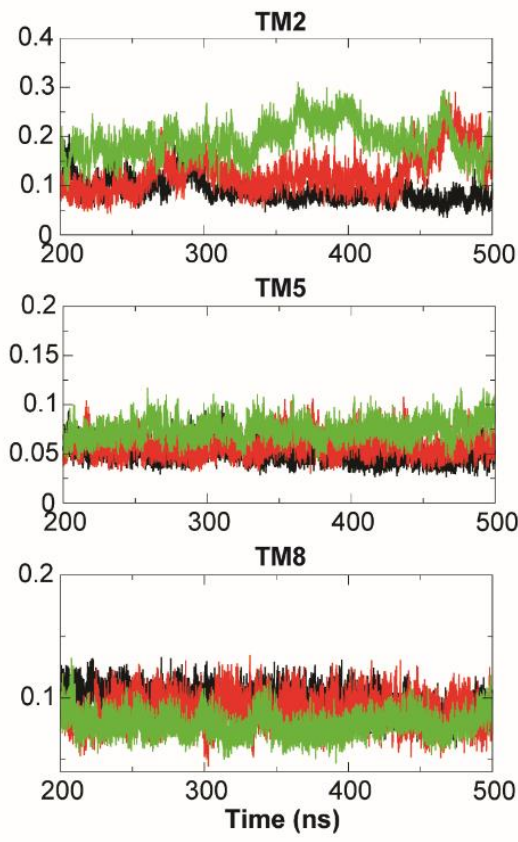

Helicity
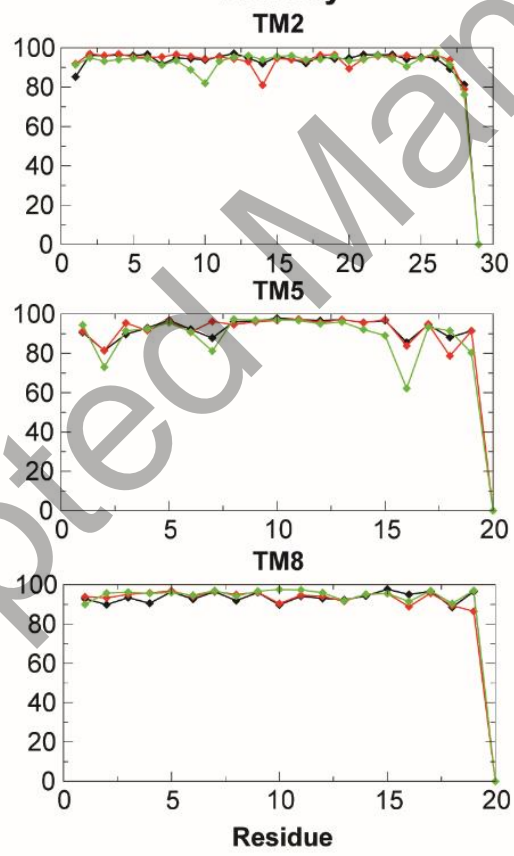
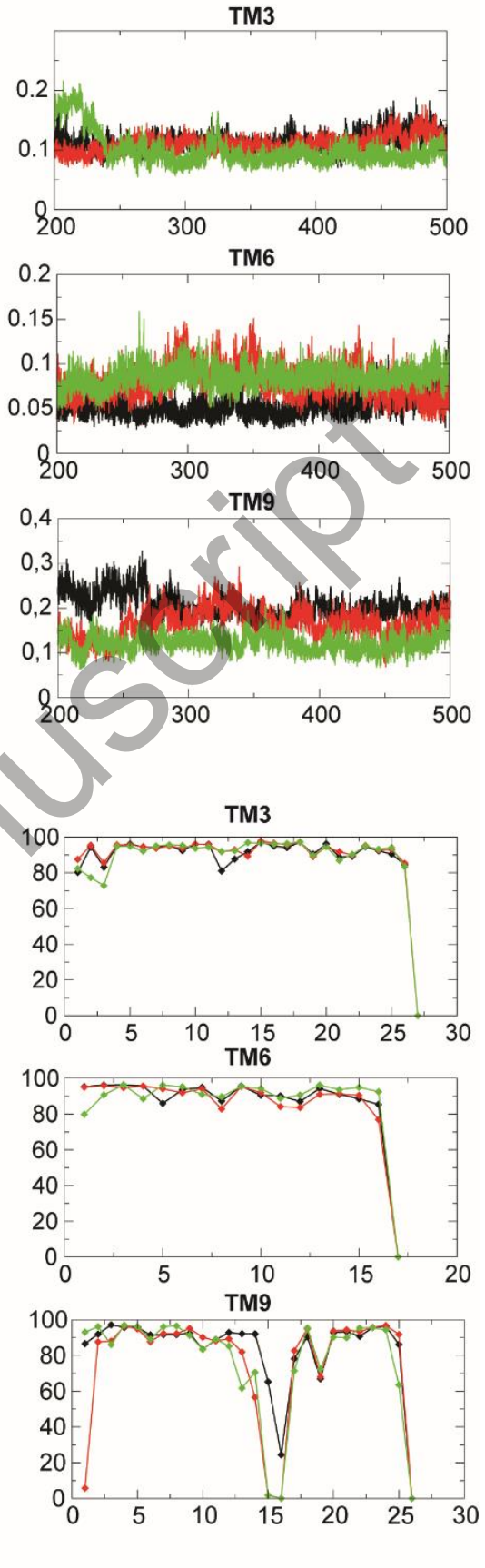

Figure 5. (A) The backbone RMSD of the nine TM helices of PS2 during the last $300 \mathrm{~ns}$ of the three independent simulations. (B) The dynamic persistence of helicity measured for the nine TM helices of PS2, with an unusual major loss of helicity seen in the middle of TM9. 
In the complete enzymatic complex, the NCT/APH-1 subunits and PEN-2 tighten the relative loose PS TM6/TM7/TM9 intramembrane cavity and rearrange the PALP motif of TM9 to the proximity of the catalytic center, thus activating the $\gamma$-secretase complex. (C. Sato et al., 2008) The present study is limited to presenilin 2 alone in lipid bilayer, for the purpose of understanding the protein alone in relation to its alone-functions.

\section{TM tilt angles in PS2 correlate with channel pore size}

The cryo-EM structures of the PS1- $\gamma$-secretase complex (5FN5, 5FN4, 5FN3, 5A63, and 5FN2)(Bai, Yan, et al., 2015; Lu et al., 2014) including those with natural single-pass TM substrates (6IYC and 6IDF)(Yang et al., 2019; Zhou et al., 2019) all reveal distinct disorder in the electron density maps of the PS1 helices, which is largely rationalized by specific dynamic motions observed in MD simulations, with most dynamics occurring in TM2, TM3, TM6, and TM9.(Somavarapu \& Kepp, 2016b, 2017) These structures were obtained in frozen ice at cryotemperatures and without the presence of a membrane. The topology is very similar in our membrane-simulated structures at ambient temperature, and thus we can argue that the thermal disorder and membrane has little effect on the topology, as expected. While membrane composition has a definite role in the allosteric modulation of the enzyme complex, the membrane packing already leads to a somewhat more compact channel and active site in PS2 alone, which is also partly due to the shorter HL2 relative to PS1 which focuses TM6 and TM7 in the membrane; we also note that the present simulation represents the immature state with intact HL2. The impact of maturation leads to a looser TM2/TM6 gate as seen by the only direct comparison of mature and immature PS1 in the literature.(Somavarapu \& Kepp, 2016b)

Recent studies have shown that the TM helix tilt angle distribution is shown correlates well with the catalytic aspartate residues in PS1. Small TM6 tilt angle values $\left(<20^{\circ}\right)$ tend to associate with smaller distances between the catalytic aspartates $(\leq 6.0 \AA)$, while with larger TM6 tilt angles have larger Asp-Asp distances.(Aguayo-Ortiz, Chávez-García, Straub, \& Dominguez, 
2017; Aguayo-Ortiz, Straub, \& Dominguez, 2018) In this study, we computed the tilt angle distribution of the TMs of PS2 and observed a wide distribution for TM2, TM3, TM7 and TM9 (Figure S11), which fits well with distributions of PS1 from available $\gamma$-secretase structures. Like PS1, the wide tilt angle distribution of TM2 and TM3 confirms the high mobility of these helices associated with the plasticity of PS2. These helices tend to move closer together upon the formation of the active site(Takeo, Watanabe, Tomita, \& Iwatsubo, 2012). The variable movements of these TM helices contribute to the large variation in the distance between the catalytic aspartates which causes imprecise or "sloppy" cleavage by the intramembrane protease. The rhomboid and site- 2 proteases which represents distinct types of intramembrane proteases have been implicated in substrate-gating/selection mechanisms (Ha, Akiyama, \& Xue, 2013; Hizukuri et al., 2014). Thus, a common mechanism may be assumed where the extracellular region of the intramembrane proteases is involved in the substrate-gating machinery. The cytosolic fragment of TM6 displayed high flexibility during all our simulations. Tominga and co-workers(Iwatsubo, Takagi-Niidome, Tominaga, Cai, \& Tomita, 2016) have shown that alterations in the distance between the cytosolic sides of TM6 and TM7 correlate with $\mathrm{A} \beta_{42}$ production. Comparatively large RMSF values (Figure 1E) and highly conserved helicity observed in TM2 and TM6 (Figure 5B) support the existence of a cooperative motion also in PS2 from our simulations.

\section{Lipid binding sites in PS2}

The presenilins hydrolyze substrates within the hydrophobic environment of the lipid bilayer at the active site (Asp-263 and Asp-366 of PS2). The crystal structures of rhomboid protease(Y. Wang, Zhang, \& Ha, 2006) and site 2 protease(Feng et al., 2007) have revealed how pores or cavities allow water to reach the catalytic residues. We expect that the active site of PS2 also accesses water molecules in the membrane-embedded cavities. To understand such interactions, we compiled the hydrogen bonds between lipids and PS2 for the three independent simulation 
systems (Figure S12) comprised of 2500 frames. The PS2 systems displayed variable trends in hydrogen-bond participation with POPC lipids due to the changes in conformation states described above. The lipid binding sites in PS2 (Table S4) in the three simulations were very diverse in nature. Most of the POPC molecules were able to freely travel around the bilayer, but some lipids were held in place by interactions with PS2 for long duration (Table S4) indicating their preference for PS2. Upon inspection of the structural ensembles obtained from cluster analysis, we found that only a few lipids interacted with the substrate recruiting domains i.e., TM2, TM6, and TM9. In contrast, accumulation of lipids near TM4 suggests that this region may play a role in accessibility to PS2 via the lipid bilayer.

\section{Structural effects of FAD-associated PS2 mutations}

Disease-associated mutations in PS1 and PS2 are known to increase the ratio of long vs. short A $\beta$ peptides, notably the $A \beta_{42} / A \beta_{40}$ ratio, in a way that correlates with clinical severity of the mutation.(Sun, Zhou, et al., 2016; Tang \& Kepp, 2018) An important question is whether this increased $A \beta_{42} / A \beta_{40}$ ratio is directly related to pathogenesis (via pathogenic $A \beta$ oligomers) as implied by the amyloid hypothesis(Selkoe \& Hardy, 2016) or a side-effect of impaired PS function, as implied by the presenilin hypothesis.(Kelleher \& Shen, 2017; Saura et al., 2004; Shen \& Kelleher, 2007) In order to understand the effect of mutation on PS2 alone rather than inside the protein complex, we used our representative structures from cluster analysis of the three independent simulations as input to map all single-amino-acid mutations and assess their impact on the stability of protein (Tables S5-S6). Altogether 39 AD-associated mutations in PS2, shown in Figure 6, were studied by structure-based computational prediction tools (out of 49 identified, three are frameshift mutations and seven could not be mapped to our PS2 structure as they locate to the elusive N-terminal). Of these 39 mutations, T122P (located in HL1), N141I (in TM2), and M239 (in TM5) are prominent pathogenic mutations consistently reported in more than one family. 

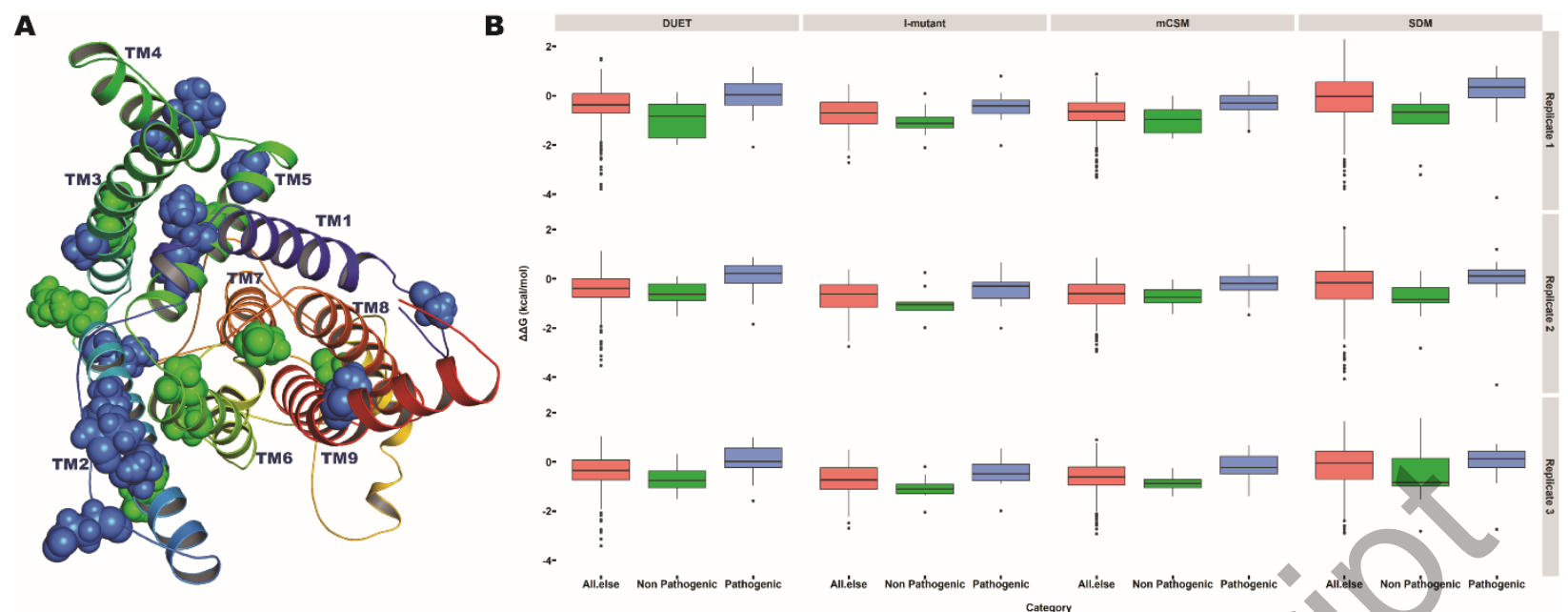

Figure 6. (A) Distribution of mutations associated AD in PS2 (Blue: pathogenic and Green: Non-pathogenic). (B) Box-whisker plot displaying the distribution of the $\Delta \Delta \mathrm{G}$ (change in the folding free energy) upon pathogenic, non-pathogenic and all other site-specific mutations computed by DUET, I-Mutant, mCSM, and SDM.

In order to assess method dependencies of our results, four structure-based mutation methods (DUET, I-Mutant, mCSM, and SDM) were used to calculate the folding stability free energy change $\Delta \Delta \mathrm{G}$ caused by pathogenic mutation (the difference in stability of the mutant and wild type protein) using all possible mutations in the variable sites as a control set. The three ensembles obtained from cluster analysis of the equilibrated trajectories were used as input (Figure 6). The $\Delta \Delta \mathrm{G}$ of pathogenic mutations distribute significantly differently from the set of all possible mutations in all the variable sites, with significantly different means as visualized in Figure 6. Despite their known uncertainties,(Kepp, 2014, 2015; Khan \& Vihinen, 2010) the methods clearly show that protein stability is reduced in most mutations and more importantly, since this is expected for a typical mutation(Tokuriki, Stricher, Schymkowitz, Serrano, \& Tawfik, 2007), significantly more so in the confirmed pathogenic mutations relative to the control set, as shown from the ANOVA summarized in Table 1. Except for the method SDM, all 
methods displayed significantly larger loss of stability for pathogenic mutations at the $95 \%$ confidence level $(\mathrm{p}<0.05)$. Thus, we conclude that AD-causing mutations in membrane-bound PS2 protein significantly reduce the fold stability of the membrane protein, which in turn is expected to affect the helix packing and overall conformational integrity of the protein.

Table 1 The results of ANOVA of four different investigated methods listed in the rightmost column, applied to the average value of $\Delta \Delta \mathrm{G}$ the three different ensembles of PS2 obtained from clustering analysis of the last $300 \mathrm{~ns}$ MD of three seeds. The groups used for ANOVA include confirmed pathogenic (15 mutations), non-pathogenic (9 mutations) and all other mutations in the affected sites (232 mutations).

\begin{tabular}{|c|c|c|c|c|c|}
\hline Mutation comparisons & $\begin{array}{c}\text { Mean } \\
\text { Difference }\end{array}$ & $\begin{array}{c}\mathbf{9 5 \%} \\
\text { Lower }\end{array}$ & $\begin{array}{c}\text { 95\% } \\
\text { Upper }\end{array}$ & p-value & Method \\
\hline Pathogenic -All else & 0.276742 & 0.047085 & 0.5064 & 0.013251 & I-mutant \\
\hline Pathogenic - Non Pathogenic & 0.564519 & 0.201055 & 0.927982 & 0.000826 & I-mutant \\
\hline Pathogenic - All else & 0.398417 & 0.144423 & 0.65241 & 0.000719 & mCSM \\
\hline Pathogenic - Non Pathogenic & 0.597852 & 0.195873 & 0.99983 & 0.001467 & mCSM \\
\hline Pathogenic - All else & 0.161762 & -0.22047 & 0.543997 & 0.581003 & SDM \\
\hline Pathogenic - Non Pathogenic & 0.719259 & 0.114322 & 1.324197 & 0.014825 & SDM \\
\hline Pathogenic - All else & 0.470881 & 0.175443 & 0.766319 & 0.000573 & DUET \\
\hline Pathogenic - Non Pathogenic & 0.786067 & 0.318497 & 1.253636 & 0.000254 & DUET \\
\hline
\end{tabular}

\section{Conclusions}

This study describes the first attempt at understanding the FAD-causing PS2 mutations in a complete structural-dynamic context. Most notably, we provide a complete model of the intact (non-mature) PS2 protein in a lipid bilayer and show that PS2 mutations mapped to this structural model tend to increase chemical properties that are likely to favor an open "pathogenic" conformation, where the Asp-Asp distance is on average larger and the pore less 
compact. A more open state might be assumed to increase membrane channel permeability, but for ions such as calcium where dehydration is a requirement for efficient membrane transport, an opening would most likely counteract dehydration and membrane transport of calcium. Our computational analysis indicates that calcium leakage in PS2(Greotti et al., 2019), which may not occur to the same extent in PS1(Shilling et al., 2012), could potentially be impaired by the same chemical properties and conformation states that also cause looser substrate binding, less activity, and higher $A \beta_{42} / 40$ ratios in the $\gamma$-secretase complex. In PS2, major dynamics are seen for TM2, TM6, TM7 and TM9, with the dynamic role of TM9 being larger than for PS1, which could relate to ion flux through the membrane(Nelson et al., 2011). Thus, if the presenilin hypothesis is correct, the increased ratio correlating to disease severity would be a confounding effect of the real pathogenic mechanism of presenilin membrane channel function. However, it is also possible that both mechanisms are relevant to disease, perhaps even in combination in a system that controls divalent metal transport across neuron and organelle membranes. We expect that our structures and dynamics of PS2 will forego experimental determination of this protein's structure and further add the membrane-protein dynamics to the picture. Thus, the residues of PS2 that we conclude are membrane exposed are in some cases likely to be sensitive to whether the membrane is there or not. This is true for a subset of the surface residues of PS2 that are horizontally exposed to the POPC bilayer in our model (Figure 1).

\section{Conflict of Interest}

The authors declare that no competing financial interest exists in relation to this work.

\section{Acknowledgements}

The authors acknowledge the financial support received from the Novo Nordisk Foundation, grant NNF17OC0028860, and the Danish Council for Independent Research | Natural Sciences (DFF), grant 7016-00079B for this work. 


\section{References}

Abraham, M. J., Murtola, T., Schulz, R., Páll, S., Smith, J. C., Hess, B., \& Lindah, E. (2015).

Gromacs: High performance molecular simulations through multi-level parallelism from laptops to supercomputers. SoftwareX, 1-2, 19-25.

https://doi.org/10.1016/j.softx.2015.06.001

Adcock, S. A., \& McCammon, J. A. (2006). Molecular dynamics: survey of methods for simulating the activity of proteins. Chemical Reviews, 106(5), 1589-1615.

Aguayo-Ortiz, R., Chávez-García, C., Straub, J. E., \& Dominguez, L. (2017). Characterizing the structural ensemble of $\gamma$-secretase using a multiscale molecular dynamics approach. Chemical Science, 8(8), 5576-5584. https://doi.org/10.1039/c7sc00980a

Aguayo-Ortiz, R., Straub, J. E., \& Dominguez, L. (2018). Influence of membrane lipid composition on the structure and activity of $\gamma$-secretase. Physical Chemistry Chemical Physics, 20(43), 27294-27304. https://doi.org/10.1039/c8cp04138e

Bai, X., Rajendra, E., Yang, G., Shi, Y., \& Scheres, S.H. (2015). Sampling the conformational space of the catalytic subunit of human $\gamma$-secretase. ELife, 4, 551-560. https://doi.org/10.7554/eLife.11182

Bai, X., Yan, C., Yang, G., Lu, P., Sun, L., Zhou, R., ... Shi, Y. (2015). An atomic structure of human $\gamma$-secretase. Nature, 525, 212-218. https://doi.org/10.1038/nature14892

Ballard, C., Gauthier, S., Corbett, A., Brayne, C., Aarsland, D., \& Jones, E. (2011). Alzheimer's disease. Lancet, 377(9770), 1019-1031. https://doi.org/10.1016/S0140-6736(10)61349-9

Begley, J. G., Duan, W., Chan, S., Duff, K., \& Mattson, M. P. (1999). Altered calcium homeostasis and mitochondrial dysfunction in cortical synaptic compartments of presenilin- 1 mutant mice. Journal of Neurochemistry, 72(3), 1030-1039.

Berendsen, H. J. C., Postma, J. P. M., van Gunsteren, W. F., DiNola, A., \& Haak, J. R. (1984). Molecular dynamics with coupling to an external bath. The Journal of Chemical Physics, 
81(8), 3684-3690. https://doi.org/10.1063/1.448118

Bolduc, D. M., Montagna, D. R., Gu, Y., Selkoe, D. J., \& Wolfe, M. S. (2016). Nicastrin functions to sterically hinder $\gamma$-secretase-substrate interactions driven by substrate transmembrane domain. Proceedings of the National Academy of Sciences, 113(5), E509E518.

Bolduc, D. M., Montagna, D. R., Seghers, M. C., Wolfe, M. S., \& Selkoe, D. J. (2016). The amyloid-beta forming tripeptide cleavage mechanism of $\gamma$-secretase. ELife, 5, e17578.

Brunello, L., Zampese, E., Florean, C., Pozzan, T., Pizzo, P., \& Fasolato, C. (2009). Presenilin2 dampens intracellular $\mathrm{Ca} 2+$ stores by increasing $\mathrm{Ca} 2+$ leakage and reducing $\mathrm{Ca} 2+$ uptake. Journal of Cellular and Molecular Medicine, 13(9b), 3358-3369.

Capriotti, E., Fariselli, P., \& Casadio, R. (2005). I-Mutant2.0: predicting stability changes upon mutation from the protein sequence or structure. Nucleic Acids Research, 33, W306-W310.

Capriotti, E., Fariselli, P., Rossi, I., \& Casadio, R. (2008). A three-state prediction of single point mutations on protein stability changes. BMC Bioinformatics, 9 Suppl 2, S6.

https://doi.org/10.1186/1471-2105-9-S2-S6

Chávez-Gutiérrez, L., Bammens, L., Benilova, I., Vandersteen, A., Benurwar, M., Borgers, M., ... De Strooper, B. (2012). The mechanism of $\gamma$-secretase dysfunction in familial Alzheimer disease. The EMBO Journal, 31(10), 2261-2274. https://doi.org/10.1038/emboj.2012.79

Chen, V. B., Arendall, W. B., Headd, J. J., Keedy, D. A., Immormino, R. M., Kapral, G. J., ... Richardson, D.C. (2010). MolProbity: All-atom structure validation for macromolecular crystallography, Acta Crystallographica D, 66(1), 12-21. https://doi.org/10.1107/S0907444909042073

Colovos, C., \& Yeates, T. O. (1993). Verification of protein structures: Patterns of nonbonded atomic interactions. Protein Science, 2(9), 1511-1519.

https://doi.org/10.1002/pro.5560020916

Contino, S., Porporato, P. E., Bird, M., Marinangeli, C., Opsomer, R., Sonveaux, P., ... Kienlen- 
Campard, P. (2017). Presenilin 2-Dependent Maintenance of Mitochondrial Oxidative Capacity and Morphology. Frontiers in Physiology, 8, 796.

https://doi.org/10.3389/fphys.2017.00796

Das, H. K., Tchedre, K., \& Mueller, B. (2012). Repression of transcription of presenilin-1 inhibits gamma-secretase independent $\mathrm{ER} \mathrm{Ca}(2)(+)$ leak that is impaired by FAD mutations. Journal of Neurochemistry, 122(3), 487-500. https://doi.org/10.1111/j.14714159.2012.07794.x

Daura, X., Gademann, K., Jaun, B., Seebach, D., Van Gunsteren, W. F., \& Mark, A. E. (1999). Peptide Folding: When Simulation Meets Experiment. Angewandte Chemie International Edition, 38(1-2), 236-240. https://doi.org/10.1002/(SICI)15213773(19990115)38:1/2<236::AID-ANIE236>3.0.CO;2-M

De Strooper, B. (2007). Loss-of-function presenilin mutations in Alzheimer disease. Talking Point on the role of presenilin mutations in Alzheimer disease. EMBO Reports, 8(2), 141146. https://doi.org/10.1038/sj.embor.7400897

De Strooper, B., Iwatsubo, T., \& Wolfe, M. S. (2012). Presenilins and $\gamma$-secretase: structure, function, and role in Alzheimer Disease. Cold Spring Harbor Perspectives in Medicine, 2, a006304. https://doi.org/10.1101/cshperspect.a006304

De Strooper, B., Saftig, P., Craessaerts, K., Vanderstichele, H., Guhde, G., Annaert, W., ... Van Leuven, F. (1998). Deficiency of presenilin-1 inhibits the normal cleavage of amyloid precursor protein. Nature, 391(6665), 387-390. https://doi.org/10.1038/34910

Duggan, S. P., \& McCarthy, J. V. (2016). Beyond $\gamma$-secretase activity: the multifunctional nature of presenilins in cell signalling pathways. Cellular Signalling, 28(1), 1-11.

Feng, L., Yan, H., Wu, Z., Yan, N., Wang, Z., Jeffrey, P. D., \& Shi, Y. (2007). Structure of a site-2 protease family intramembrane metalloprotease. Science, 318(5856), 1608-1612. https://doi.org/10.1126/science.1150755

Filadi, R., Greotti, E., Turacchio, G., Luini, A., Pozzan, T., \& Pizzo, P. (2016). Presenilin 2 
Modulates Endoplasmic Reticulum-Mitochondria Coupling by Tuning the Antagonistic Effect of Mitofusin 2. Cell Reports, 15(10), 2226-2238. https://doi.org/10.1016/J.CELREP.2016.05.013

Finckh, U., Müller-Thomsen, T., Mann, U., Eggers, C., Marksteiner, J., Meins, W., ... Gal, A. (2000). High Prevalence of Pathogenic Mutations in Patients with Early-Onset Dementia Detected by Sequence Analyses of Four Different Genes. The American Journal of Human Genetics, 66(1), 110-117. https://doi.org/10.1086/302702

Greotti, E., Capitanio, P., Wong, A., Pozzan, T., Pizzo, P., \& Pendin, D. (2019). Familial Alzheimer's disease-linked presenilin mutants and intracellular $\mathrm{Ca} 2+$ handling: A singleorganelle, FRET-based analysis. Cell Calcium, 79, 44-56. https://doi.org/https://doi.org/10.1016/j.ceca.2019.02.005

Guo, Q., Furukawa, K., Sopher, B. L., Pham, D. G., Xie, J., Robinson, N., ... Mattson, M. P. (1996). Alzheimer's PS-1 mutation perturbs calcium homeostasis and sensitizes PC12 cells to death induced by amyloid beta-peptide. Neuroreport, 8(1), 379-383.

Ha, Y., Akiyama, Y., \& Xue, Y. (2013, May). Structure and mechanism of rhomboid protease. Journal of Biological Chemistry. American Society for Biochemistry and Molecular Biology. https://doi.org/10.1074/jbc.R112.422378

Hekkelman, M. L., te Beek, T.A. H., Pettifer, S. R., Thorne, D., Attwood, T. K., \& Vriend, G. (2010). WIWS: A protein structure bioinformatics web service collection. Nucleic Acids Research, 38(SUPPL. 2), 719-723. https://doi.org/10.1093/nar/gkq453

Heo, L., Park, H., \& Seok, C. (2013). GalaxyRefine: Protein structure refinement driven by sidechain repacking. Nucleic Acids Research, 41(Web Server issue), W384-W388. https://doi.org/10.1093/nar/gkt458

Hizukuri, Y., Oda, T., Tabata, S., Tamura-Kawakami, K., Oi, R., Sato, M., ... Nogi, T. (2014). A structure-based model of substrate discrimination by a noncanonical PDZ tandem in the intramembrane-cleaving protease RseP. Structure, 22(2), 326-336. 
https://doi.org/10.1016/j.str.2013.12.003

Holmes, O., Paturi, S., Selkoe, D. J., \& Wolfe, M. S. (2014). Pen-2 is essential for $\gamma$-secretase complex stability and trafficking but partially dispensable for endoproteolysis.

Biochemistry, 53(27), 4393-4406. https://doi.org/10.1021/bi500489j

Holmes, O., Paturi, S., Ye, W., Wolfe, M. S., \& Selkoe, D. J. (2012). Effects of membrane lipids on the activity and processivity of purified $\gamma$-secretase. Biochemistry, 51(17), 3565-3575. https://doi.org/10.1021/bi300303g

Honarnejad, K., \& Herms, J. (2012). Presenilins: role in calcium homeostasis. The International Journal of Biochemistry \& Cell Biology, 44(11), 1983-1986. https://doi.org/10.1016/j.biocel.2012.07.019

Huang, J., Rauscher, S., Nawrocki, G., Ran, T., Feig, M., De Groot, B. L., ... MacKerell, A. D. (2016). CHARMM36m: An improved force field for folded and intrinsically disordered proteins. Nature Methods, 14(1), 71-73. https://doi.org/10.1038/nmeth.4067

Humphrey, W., Dalke, A., \& Schulten, K. (1996). VMD: visual molecular dynamics. Journal of Molecular Graphics, 14(1), 33-38.

Iwatsubo, T., Takagi-Niidome, S., Tominaga, A., Cai, T., \& Tomita, T. (2016). Conformational Changes in Transmembrane Domain 4 of Presenilin 1 Are Associated with Altered Amyloid- 42 Production. Journal of Neuroscience, 36(4), 1362-1372. https://doi.org/10.1523/jneurosci.5090-14.2016

Jo, S., Kim, T., Iyer, V. G., \& Im, W. (2008). CHARMM-GUI: A web-based grraphical user interface for CHARMM. Journal of Computational Chemistry, 29(11), 1859-1865. https://doi.org/10.1002/jcc.20945

Kelleher, R. J., \& Shen, J. (2017). Presenilin-1 mutations and Alzheimer's disease. Proceedings of the National Academy of Sciences, 114(4), 629-631. Retrieved from http://www.pnas.org/content/114/4/629.abstract

Kepp, K. P. (2014). Computing stability effects of mutations in human superoxide dismutase 1. 
The Journal of Physical Chemistry. B, 118(7), 1799-1812.

https://doi.org/10.1021/jp4119138

Kepp, K. P. (2015). Towards a "Golden Standard” for computing globin stability: Stability and structure sensitivity of myoglobin mutants. Biochimica et Biophysica Acta (BBA) - Proteins and Proteomics, 1854(10), 1239-1248. https://doi.org/10.1016/j.bbapap.2015.06.002

Kepp, K. P. (2017). Ten Challenges of the Amyloid Hypothesis of Alzheimer's Disease. Journal of Alzheimer's Disease, 55(2), 447-457. https://doi.org/10.3233/JAD-160550

Khachaturian, Z. S. (1987). Hypothesis on the regulation of cytosol calcium concentration and the aging brain. Neurobiology of Aging, 8(4), 345-346.

Khan, S., \& Vihinen, M. (2010). Performance of protein stability predictors. Human Mutation, 31(6), 675-684. https://doi.org/10.1002/humu.21242

Knappenberger, K. S., Tian, G., Ye, X., Sobotka-Briner, C., Ghanekar, S. V, Greenberg, B. D., $\&$ Scott, C. W. (2004). Mechanism of $\gamma$-secretase cleavage activation: is $\gamma$-secretase regulated through autoinhibition involving the presenilin-1 exon 9 loop? Biochemistry, 43(20), 6208-6218. https://doi.org/10.1021/bi036072v

Kong, R., Chang, S., Xia, W., \& Wong, S. T. C. (2015). Molecular dynamics simulation study reveals potential substrate entry path into gamma-secretase/presenilin-1. Journal of Structural Biology, 191(2), 120-129. https://doi.org/10.1016/j.jsb.2015.07.001

Kusiak, J. W., Sunderland, T., Ganjei, J. K., Iwasaki, K., Wasco, W., Lacana, E., ... D’Adamio, L. (2002). Participation of Presenilin 2 in Apoptosis: Enhanced Basal Activity Conferred by an Alzheimer Mutation. Science, 274(5293), 1710-1713. https://doi.org/10.1126/science.274.5293.1710

LaFerla, F. M. (2002). Calcium dyshomeostasis and intracellular signalling in Alzheimer's disease. Nature Reviews Neuroscience, 3(11), 862.

Lai, M. T., Chen, E., Crouthamel, M. C., DiMuzio-Mower, J., Xu, M., Huang, Q., ... Li, Y. M. (2003a). Presenilin-1 and presenilin-2 exhibit distinct yet overlapping $\gamma$-secretase activities. 
Journal of Biological Chemistry, 278(25), 22475-22481.

https://doi.org/10.1074/jbc.M300974200

Lai, M. T., Chen, E., Crouthamel, M. C., DiMuzio-Mower, J., Xu, M., Huang, Q., ... Li, Y. M. (2003b). Presenilin-1 and presenilin-2 exhibit distinct yet overlapping $\gamma$-secretase activities. Journal of Biological Chemistry, 278(25), 22475-22481. https://doi.org/10.1074/jbc.M300974200

Laimer, J., Hofer, H., Fritz, M., Wegenkittl, S., \& Lackner, P. (2015). MAESTRO - multi agent stability prediction upon point mutations. BMC Bioinformatics, 16(1), 116. https://doi.org/10.1186/s12859-015-0548-6

Laskowski, R. A., MacArthur, M. W., Moss, D. S., Thornton, J. M., \& IUCr.(1993).

PROCHECK: a program to check the stereochemical quality of protein structures. Journal of Applied Crystallography, 26(2), 283-291. https://doi.org/10.1107/S0021889892009944

Lee, M. K., Slunt, H. H., Martin, L. J., Thinakaran, G., Kim, G., Gandy, S. E., ... Sisodia, S. S. (1996). Expression of presenilin 1 and 2 (PS1 and PS2) in human and murine tissues. The Journal of Neuroscience: The Official Journal of the Society for Neuroscience, 16(23), 7513-25. https://doi.org/10.1523/JNEUROSCI.16-23-07513.1996

Leissring, M. A., Akbari, Y., Fanger, C.M., Cahalan, M. D., Mattson, M. P., \& LaFerla, F. M. (2000). Capacitative calcium entry deficits and elevated luminal calcium content in mutant presenilin-1 knockin mice. The Journal of Cell Biology, 149(4), 793-798.

Leissring, M. A., Parker, I., \& LaFerla, F. M. (1999). Presenilin-2 mutations modulate amplitude and kinetics of inositol 1,4,5-trisphosphate-mediated calcium signals. Journal of Biological Chemistry, 274(46), 32535-32538. https://doi.org/10.1074/jbc.274.46.32535

Levy-Lahad, E., Wasco, W., Poorkaj, P., Romano, D. M., Oshima, J., Pettingell, W. H., ... et al. (1995). Candidate gene for the chromosome 1 familial Alzheimer's disease locus. Science, 269(5226), 973-977. https://doi.org/10.1126/science.7638622

Li, X., Dang, S., Yan, C., Gong, X., Wang, J., \& Shi, Y. (2013). Structure of a presenilin family 
intramembrane aspartate protease. Nature, 493(7430), 56-61.

https://doi.org/10.1038/nature11801

Lomize, A. L., Pogozheva, I. D., Lomize, M. A., \& Mosberg, H. I. (2006). Positioning of proteins in membranes: A computational approach. Protein Science, 15(6), 1318-1333. https://doi.org/10.1110/ps.062126106

Lomize, M. A., Pogozheva, I. D., Joo, H., Mosberg, H. I., \& Lomize, A. L. (2012). OPM database and PPM web server: Resources for positioning of proteins in membranes. Nucleic Acids Research, 40(D1), D370-D376. https://doi.org/10.1093/nar/gkr703

Lu, P., Bai, X., Ma, D., Xie, T., Yan, C., Sun, L., ... Shi, Y. (2014). Three-dimensional structure of human $\gamma$-secretase. Nature, 512(7513), 166-170. https://doi.org/10.1038/nature13567 Lyubartsev, A. P., \& Rabinovich, A. L. (2016). Force Field Development for Lipid Membrane Simulations. Biochimica et Biophysica Acta (BBA) - Biomembranes, 1858(10), 2483-2497. https://doi.org/10.1016/J.BBAMEM.2015.12.033

Martyna, G. J., Klein, M. L., \& Tuckerman, M. (1992). Nosé-Hoover chains: The canonical ensemble via continuous dynamics. The Journal of Chemical Physics, 97(4), 2635-2643.

Mattson, M. P. (2010). ER calcium and Alzheimer's disease: in a state of flux. Science Signaling, 3(114), pe10. https://doi.org/10.1126/scisignal.3114pe10

Nelson, O., Supnet, C., Tolia, A., Horré, K., De Strooper, B., \& Bezprozvanny, I. (2011). Mutagenesis mapping of the presenilin 1 calcium leak conductance pore. The Journal of Biological Chemistry,286(25), 22339-22347. https://doi.org/10.1074/jbc.M111.243063

Nichols, E., Szoeke, C. E. I., Vollset, S. E., Abbasi, N., Abd-Allah, F., Abdela, J., ... Murray, C. J. L. (2019). Global, regional, and national burden of Alzheimer's disease and other dementias, 1990-2016: a systematic analysis for the Global Burden of Disease Study 2016. The Lancet Neurology, 18(1), 88-106. https://doi.org/10.1016/S1474-4422(18)30403-4

Pandurangan, A. P., Ochoa-Montaño, B., Ascher, D. B., \& Blundell, T. L. (2017). SDM: A server for predicting effects of mutations on protein stability. Nucleic Acids Research, 
45(W1), W229-W235. https://doi.org/10.1093/nar/gkx439

Parrinello, M., \& Rahman, A. (1981). Polymorphic Transitions in Single Crystals: a New Molecular Dynamics Method. Journal of Applied Physics, 52(12), 7182-7190. https://doi.org/10.1063/1.328693

Pires, D. E., Ascher, D. B., \& Blundell, T. L. (2013). mCSM: predicting the effects of mutations in proteins using graph-based signatures. Bioinformatics, 30(3), 335-342. https://doi.org/10.1093/bioinformatics/btt691

Pires, D. E. V, Ascher, D. B., \& Blundell, T. L. (2014). DUET: a server for predicting effects of mutations on protein stability using an integrated computational approach. Nucleic Acids Research, gku411.

Raven, F., Ward, J. F., Zoltowska, K. M., Wan, Y., Bylykbashi, E., Miller, S. J., ... Zhang, C. (2017). Soluble Gamma-secretase Modulators Attenuate Alzheimer’s $\beta$-amyloid Pathology and Induce Conformational Changes in Presenilin 1. EBioMedicine, 24, 93-101. https://doi.org/10.1016/j.ebiom.2017.08.028

Rodrigues, C. H., Pires, D. E., \& Ascher, D. B. (2018). DynaMut: predicting the impact of mutations on protein conformation, flexibility and stability. Nucleic Acids Research, 46(W1), W350-W355. https://doi.org/10.1093/nar/gky300

Rogaev, E. I., Sherrington, R., Rogaeva, E. A., Levesque, G., Ikeda, M., Liang, Y., ... Tsuda, T. (1995). Familial Alzheimer's disease in kindreds with missense mutations in a gene on chromosome 1 related to the Alzheimer's disease type 3 gene. Nature, 376(6543), 775-778. https://doi.org/10.1038/376775a0

Ryman, D. C., Acosta-Baena, N., Aisen, P. S., Bird, T., Danek, A., Fox, N. C., ... Bateman, R. J. (2014). Symptom onset in autosomal dominant Alzheimer disease: A systematic review and meta-analysis. Neurology, 83, 253-260. https://doi.org/10.1212/WNL.0000000000000596

Sato, C., Takagi, S., Tomita, T., \& Iwatsubo, T. (2008). The C-Terminal PAL Motif and Transmembrane Domain 9 of Presenilin 1 Are Involved in the Formation of the Catalytic 
Pore of the $\gamma$-Secretase. Journal of Neuroscience, 28(24), 6264-6271.

https://doi.org/10.1523/JNEUROSCI.1163-08.2008

Sato, T., Diehl, T. S., Narayanan, S., Funamoto, S., Ihara, Y., De Strooper, B., ... Wolfe, M. S. (2007). Active $\gamma$-secretase complexes contain only one of each component. Journal of Biological Chemistry, 282(47), 33985-33993. https://doi.org/10.1074/jbc.M705248200

Saura, C. A., Choi, S.-Y., Beglopoulos, V., Malkani, S., Zhang, D., Shankaranarayana Rao, B. S., ... Shen, J. (2004). Loss of presenilin function causes impairments of memory and synaptic plasticity followed by age-dependent neurodegeneration. Neuron, 42(1), 23-36.

Selkoe, D. J., \& Hardy, J. (2016). The amyloid hypothesis of Alzheimer's disease at 25 years. EMBO Molecular Medicine, 8(6), 595-608. https://doi.org/10.15252/emmm.201606210

Shah, S., Lee, S.-F., Tabuchi, K., Hao, Y.-H., Yu, C., LaPlant, Q., .. Yu, G. (2005). Nicastrin Functions as a $\gamma$-Secretase-Substrate Receptor. Cell, 122(3), 435-447. https://doi.org/10.1016/j.cell.2005.05.022

Shen, J., \& Kelleher, R. J. (2007). The presenilin hypothesis of Alzheimer's disease: evidence for a loss-of-function pathogenic mechanism. Proceedings of the National Academy of Sciences of the United States of America, 104(2), 403-409. https://doi.org/10.1073/pnas.0608332104

Shilling, D., Mak, D.-O. D., Kang, D. E., \& Foskett, J. K. (2012). Lack of evidence for presenilins as endoplasmic reticulum $\mathrm{Ca} 2+$ leak channels. The Journal of Biological Chemistry, 287(14), 10933-10944. https://doi.org/10.1074/jbc.M111.300491

Somavarapu, A. K., \& Kepp, K. P. (2016a). Loss of stability and hydrophobicity of presenilin 1 mutations causing Alzheimer's Disease. Journal of Neurochemistry, 137, 101-111. https://doi.org/10.1111/jnc.13535

Somavarapu, A. K., \& Kepp, K. P. (2016b). The dynamic mechanism of presenilin-1 function: Sensitive gate dynamics and loop unplugging control protein access. Neurobiology of Disease, 89, 147-156. https://doi.org/10.1016/j.nbd.2016.02.008 
Somavarapu, A. K., \& Kepp, K. P. (2017). Membrane Dynamics of $\gamma$-Secretase Provides a Molecular Basis for $\beta$-Amyloid Binding and Processing. ACS Chemical Neuroscience, 8(11), 2424-2436. https://doi.org/10.1021/acschemneuro.7b00208

Sun, L., Li, X., \& Shi, Y. (2016). Structural biology of intramembrane proteases: mechanistic insights from rhomboid and S2P to $\gamma$-secretase. Current Opinion in Structural Biology, 37, 97-107. https://doi.org/10.1016/J.SBI.2015.12.008

Sun, L., Zhao, L., Yang, G., Yan, C., Zhou, R., Zhou, X., ... Shi, Y. (2015). Structural basis of human $\gamma$-secretase assembly. Proceedings of the National Academy of Sciences of the United States of America, 112(19), 6003-6008. https://doi.org/10.1073/pnas.1506242112

Sun, L., Zhou, R., Yang, G., \& Shi, Y. (2016). Analysis of 138 pathogenic mutations in presenilin- 1 on the in vitro production of $A \beta 42$ and $A \beta 40$ peptides by $\gamma$-secretase. Proceedings of the National Academy of Sciences, 114(4), E476-E485. https://doi.org/10.1073/pnas.1618657114

Szaruga, M., Munteanu, B., Lismont, S., Veugelen, S., Horré, K., Mercken, M., ... Strooper, B. De. (2017). Alzheimer's-Causing Mutations Shift A $\beta$ Length by Destabilizing $\gamma$-SecretaseA $\beta$ n Interactions. Cell, 170(3), 443-456.

Takami, M., Nagashima, Y., Sano, Y., Ishihara, S., Morishima-Kawashima, M., Funamoto, S., \& Ihara, Y. (2009). $\gamma$-Secretase: successive tripeptide and tetrapeptide release from the transmembrane domain of $\beta$-carboxyl terminal fragment. The Journal of Neuroscience, 29(41), 13042-13052. https://doi.org/10.1523/JNEUROSCI.2362-09.2009

Takeo, K., Watanabe, N., Tomita, T., \& Iwatsubo, T. (2012). Contribution of the $\gamma$-secretase subunits to the formation of catalytic pore of presenilin 1 protein. Journal of Biological Chemistry, 287(31), 25834-25843. https://doi.org/10.1074/jbc.M111.336347

Tang, N., \& Kepp, K. P. (2018). A $\beta 42 / A \beta 40$ ratios of presenilin 1 mutations correlate with clinical onset of Alzheimer's disease. Journal of Alzheimer's Disease, 66(3), 939-945.

Tang, N., Somavarapu, A. K., \& Kepp, K. P. (2018). Molecular Recipe for $\gamma$-Secretase 
Modulation from Computational Analysis of 60 Active Compounds. ACS Omega, 3(12), 18078-18088. https://doi.org/10.1021/acsomega.8b02196

Tokuriki, N., Stricher, F., Schymkowitz, J., Serrano, L., \& Tawfik, D. S. (2007). The stability effects of protein mutations appear to be universally distributed. Journal of Molecular Biology, 369(5), 1318-1332. https://doi.org/10.1016/j.jmb.2007.03.069

Tolia, A., Horré, K., \& De Strooper, B. (2008). Transmembrane domain 9 of presenilin determines the dynamic conformation of the catalytic site of $\gamma$-secretase. Journal of Biological Chemistry, 283(28), 19793-19803. https://doi.org/10.1074/jbc.M802461200

Tomita, T. (2014). Molecular mechanism of intramembrane proteolysis by $\gamma$-secretase. Journal of Biochemistry, 156(4), 195-201. https://doi.org/10.1093/jb/mvu049

Tu, H., Nelson, O., Bezprozvanny, A., Wang, Z., Lee, S.-F., Hao, Y.-H.,... Bezprozvanny, I. (2006). Presenilins form ER Ca2+ leak channels, a function disrupted by familial Alzheimer's disease-linked mutations. Cell, 126(5), 981-993. https://doi.org/10.1016/j.cell.2006.06.059

Uemura, K., Lill, C. M., Li, X., Peters, J. A., Ivanov, A., Fan, Z., ... Berezovska, O. (2009). Allosteric modulation of PS1/ $\gamma$-secretase conformation correlates with amyloid $\beta 42 / 40$ ratio. PloS One, 4(11), e7893.

Vassar, R., Bennett, B. D., Babu-Khan, S., Kahn, S., Mendiaz, E. A., Denis, P., ... Citron, M. (1999). Beta-secretase cleavage of Alzheimer's amyloid precursor protein by the transmembrane aspartic protease BACE. Science (New York, N.Y.), 286(5440), 735-741. https://doi.org/10.1126/science.286.5440.735

Wahlster, L., Arimon, M., Nasser-Ghodsi, N., Post, K. L., Serrano-Pozo, A., Uemura, K., \& Berezovska, O. (2013). Presenilin-1 adopts pathogenic conformation in normal aging and in sporadic Alzheimer's disease. Acta Neuropathologica, 125(2), 187-199.

Walker, E. S., Martinez, M., Brunkan, A. L., \& Goate, A. (2005). Presenilin 2 familial Alzheimer's disease mutations result in partial loss of function and dramatic changes in $\mathrm{A} \beta$ 
42/40 ratios. Journal of Neurochemistry, 92(2), 294-301. https://doi.org/10.1111/j.14714159.2004.02858.x

Wallner, B., \& Elofsson, A. (2003). Can correct protein models be identified? Protein Science, 12(5), 1073-1086. https://doi.org/10.1110/ps.0236803

Wang, J., Beher, D., Nyborg, A. C., Shearman, M. S., Golde, T. E., \& Goate, A. (2006). Cterminal PAL motif of presenilin and presenilin homologues required for normal active site conformation. Journal of Neurochemistry, 96(1), 218-227. https://doi.org/10.1111/j.14714159.2005.03548.x

Wang, Y., Zhang, Y., \& Ha, Y. (2006). Crystal structure of a rhomboid family intramembrane protease. Nature, 444(7116), 179-180. https://doi.org/10.1038/nature05255

Watanabe, N., Takagi, S., Tominaga, A., Tomita, T., \& Iwatsubo, T. (2010). Functional analysis of the transmembrane domains of presenilin 1: Participation of transmembrane domains 2 and 6 in the formation of initial substrate-binding site of $\gamma$-secretase. Journal of Biological Chemistry, 285, 19738-19746. https://doi.org/10.1074/jbc.M110.101287

Webb, B., \& Sali, A. (2017). Protein structure modeling with MODELLER. In Methods in Molecular Biology (Vol. 1654, pp. 39-54). Humana Press, New York, NY. https://doi.org/10.1007/978-1-4939-7231-9_4

Wiederstein, M., \& Sippl, M. J. (2007). ProSA-web: Interactive web service for the recognition of errors in three-dimensional structures of proteins. Nucleic Acids Research, 35(SUPPL.2), 407-410. https://doi.org/10.1093/nar/gkm290

Wolfe, M. S., Xia, W., Ostaszewski, B. L., Diehl, T. S., Kimberly, W. T., \& Selkoe, D. J. (1999). Two transmembrane aspartates in presenilin-1 required for presenilin endoproteolysis and $\gamma$-secretase activity. Nature, 398(6727), 513-517. https://doi.org/10.1038/19077

Worth, C. L., Preissner, R., \& Blundell, T. L. (2011). SDM--a server for predicting effects of mutations on protein stability and malfunction. Nucleic Acids Research, 39(Web Server issue), W215-W222. https://doi.org/10.1093/nar/gkr363 
Yang, G., Zhou, R., Zhou, Q., Guo, X., Yan, C., Ke, M., ... Shi, Y. (2019). Structural basis of Notch recognition by human $\gamma$-secretase. Nature, 565(7738), 192-197. https://doi.org/10.1038/s41586-018-0813-8

Zampese, E., Fasolato, C., Kipanyula, M. J., Bortolozzi, M., Pozzan, T., \& Pizzo, P. (2011). Presenilin 2 modulates endoplasmic reticulum (ER)-mitochondria interactions and $\mathrm{Ca} 2+$ cross-talk. Proceedings of the National Academy of Sciences, 108(7), 2777-2782. https://doi.org/10.1073/pnas.1100735108

Zatti, G., Burgo, A., Giacomello, M., Barbiero, L., Ghidoni, R., Sinigaglia, G., ... Sorbi, S. (2006). Presenilin mutations linked to familial Alzheimer's disease reduce endoplasmic reticulum and Golgi apparatus calcium levels. Cell Calcium, 39(6), 539-550.

Zhang, H., Sun, S., Herreman, A., De Strooper, B., \& Bezprozvanny, I. (2010). Role of Presenilins in Neuronal Calcium Homeostasis. The Journal of Neuroscience, 30(25), 8566 LP-8580. https://doi.org/10.1523/JNEUROSCI.1554-10.2010

Zhang, Y., \& Cremer, P. S. (2006). Interactions between macromolecules and ions: the Hofmeister series. Current Opinion in Chemical Biology, 10(6), 658-663.

Zhou, R., Yang, G., Guo, X., Zhou, Q., Lei, J., \& Shi, Y. (2019). Recognition of the amyloid precursor protein by human $\gamma$-secretase. Science, 363(6428), eaaw0930. https://doi.org/10.1126/science.aaw0930

Zhuang, X., Dávila-Contreras, E. M., Beaven, A. H., Im, W., \& Klauda, J. B. (2016). An extensive simulation study of lipid bilayer properties with different head groups, acyl chain lengths, and chain saturations. Biochimica et Biophysica Acta - Biomembranes, 1858(12), 3093-3104. https://doi.org/10.1016/j.bbamem.2016.09.016

Zhuang, X., Makover, J. R., Im, W., \& Klauda, J. B. (2014). A systematic molecular dynamics simulation study of temperature dependent bilayer structural properties. Biochimica et Biophysica Acta - Biomembranes, 1838(10), 2520-2529. https://doi.org/10.1016/j.bbamem.2014.06.010 
Table S1. Thickness of the POPC membrane averaged over 500 ns MD of the PS2-membrane system.

\begin{tabular}{|l|l|l|l|}
\hline System & Membrane & Lower leaflet & Upper leaflet \\
\hline Simulation 1 & $3.918 \pm 0.068 \mathrm{~nm}$ & $3.914 \pm 0.068 \mathrm{~nm}$ & $3.922 \pm 0.073 \mathrm{~nm}$ \\
\hline Simulation 2 & $3.947 \pm 0.068 \mathrm{~nm}$ & $3.951 \pm 0.071 \mathrm{~nm}$ & $3.943 \pm 0.073 \mathrm{~nm}$ \\
\hline Simulation 3 & $3.973 \pm 0.074 \mathrm{~nm}$ & $3.935 \pm 0.076 \mathrm{~nm}$ & $3.939 \pm 0.076 \mathrm{~nm}$ \\
\hline
\end{tabular}

Table S2. Computed area per lipid of the POPC membrane, averaged over 500 ns of MD simulation.

\begin{tabular}{|l|l|l|l|}
\hline System & Membrane & Lower leaflet & Upper leaflet \\
\hline Simulation 1 & $0.628 \pm 0.011 \mathrm{~nm}^{2}$ & $0.627 \pm 0.014 \mathrm{~nm}^{2}$ & $0.627 \pm 0.014 \mathrm{~nm}^{2}$ \\
\hline Simulation 2 & $0.623 \pm 0.011 \mathrm{~nm}^{2}$ & $0.617 \pm 0.014 \mathrm{~nm}^{2}$ & $0.630 \pm 0.013 \mathrm{~nm}^{2}$ \\
& & & \\
\hline Simulation 3 & $0.627 \pm 0.012 \mathrm{~nm}^{2}$ & $0.629 \pm 0.014 \mathrm{~nm}^{2}$ & $0.624 \pm 0.014 \mathrm{~nm}^{2}$ \\
\hline
\end{tabular}

Table S3. Area of the POPC membrane averaged over $500 \mathrm{~ns}$ of MD simulation.

\begin{tabular}{|l|l|l|l|}
\hline System & Membrane & Lower leaflet & Upper leaflet \\
\hline Simulation 1 & $59.361 \pm 1.019 \mathrm{~nm}^{2}$ & $59.762 \pm 1.284 \mathrm{~nm}^{2}$ & $58.960 \pm 1.290 \mathrm{~nm}^{2}$ \\
\hline Simulation 2 & $58.919 \pm 1.060 \mathrm{~nm}^{2}$ & $58.586 \pm 1.317 \mathrm{~nm}^{2}$ & $59.251 \pm 1.218 \mathrm{~nm}^{2}$ \\
\hline Simulation 3 & $59.226 \pm 1.161 \mathrm{~nm}^{2}$ & $59.764 \pm 1.348 \mathrm{~nm}^{2}$ & $58.689 \pm 1.310 \mathrm{~nm}^{2}$ \\
\hline
\end{tabular}

Table S4. Occupancy of hydrogen bonds between amino acid residues of the PS2 and POPC lipids of the membrane during $500 \mathrm{~ns}$ of MD simulation computed using 2500 frames from each trajectory (only residue pairs showing occupancy $>10 \%$ are displayed in the Table).

\begin{tabular}{|c|c|c|c|c|c|c|c|c|}
\hline \multicolumn{3}{|c|}{ Simulation 1} & \multicolumn{3}{|c|}{ Simulation 2} & \multicolumn{3}{|c|}{ Simulation 3} \\
\hline Donor & Acceptor & Occupancy & Donor & Acceptor & Occupancy & Donor & Acceptor & Occupancy \\
\hline SER108-Side & POPC454-Side & $11.70 \%$ & LYS86-Side & POPC556-Side & $19.36 \%$ & TYR165-Side & POPC618-Side & $10.38 \%$ \\
\hline ARG163-Side & POPC544-Side & $29.30 \%$ & TYR83-Main & POPC552-Side & $35.65 \%$ & TYR185-Side & POPC461-Side & $36.41 \%$ \\
\hline LYS161-Side & POPC545-Side & $15.69 \%$ & LYS86-Side & POPC606-Side & $33.53 \%$ & ARG110-Side & POPC451-Side & $12.53 \%$ \\
\hline LYS107-Side & POPC451-Side & $24.51 \%$ & LYS166-Side & POPC547-Side & $16.93 \%$ & LYS86-Side & POPC557-Side & $13.37 \%$ \\
\hline TYR195-Side & POPC454-Side & $17.09 \%$ & ARG163-Side & POPC590-Side & $28.06 \%$ & LYS161-Side & POPC545-Side & $15.85 \%$ \\
\hline ARG134-Side & POPC450-Side & $28.06 \%$ & LYS271-Side & POPC553-Side & $11.54 \%$ & ARG358-Side & POPC557-Side & $20.56 \%$ \\
\hline TYR185-Side & POPC461-Side & $15.25 \%$ & GLY84-Main & POPC552-Side & $13.77 \%$ & LYS86-Side & POPC550-Side & $11.82 \%$ \\
\hline GLN118-Side & POPC465-Side & $13.21 \%$ & ARG163-Side & POPC544-Side & $11.26 \%$ & LYS107-Side & POPC451-Side & $16.73 \%$ \\
\hline HSD220-Side & POPC547-Side & $10.58 \%$ & TYR185-Side & POPC461-Side & $18.04 \%$ & TYR201-Side & POPC461-Side & $16.09 \%$ \\
\hline LYS86-Side & POPC550-Side & $15.37 \%$ & ASP200-Main & POPC449-Side & $16.53 \%$ & ARG275-Side & POPC560-Side & $10.58 \%$ \\
\hline LEU225-Main & POPC556-Side & $11.42 \%$ & LYS161-Side & POPC554-Side & $29.22 \%$ & SER130-Side & POPC455-Side & $16.57 \%$ \\
\hline ARG134-Side & POPC479-Side & $42.51 \%$ & ARG163-Side & POPC548-Side & $32.34 \%$ & ARG284-Side & POPC549-Side & $10.14 \%$ \\
\hline TRP221-Side & POPC551-Side & $19.04 \%$ & LYS245-Side & POPC452-Side & $14.41 \%$ & ARG163-Side & POPC565-Side & $18.88 \%$ \\
\hline LYS166-Side & POPC548-Side & $15.45 \%$ & ASN386-Side & POPC456-Side & $27.11 \%$ & LYS410-Side & POPC553-Side & $11.70 \%$ \\
\hline LYS245-Side & POPC452-Side & $23.91 \%$ & LYS82-Side & POPC552-Side & $20.20 \%$ & ARG134-Side & POPC450-Side & $12.10 \%$ \\
\hline TYR83-Side & POPC543-Side & $17.49 \%$ & LYS86-Side & POPC550-Side & $12.77 \%$ & TYR262-Side & POPC560-Side & $13.93 \%$ \\
\hline LYS86-Side & POPC559-Side & $18.44 \%$ & LYS271-Side & POPC566-Side & $16.01 \%$ & TRP221-Side & POPC571-Side & $22.00 \%$ \\
\hline LYS161-Side & POPC560-Side & $35.77 \%$ & SER130-Side & POPC464-Side & $32.89 \%$ & LYS245-Side & POPC452-Side & $43.15 \%$ \\
\hline TYR83-Main & POPC552-Side & $25.87 \%$ & GLY132-Main & POPC464-Side & $11.74 \%$ & TYR162-Side & POPC580-Side & $13.13 \%$ \\
\hline ARG163-Side & POPC590-Side & $12.26 \%$ & TYR246-Side & POPC452-Side & $27.43 \%$ & ARG163-Side & POPC570-Side & $20.28 \%$ \\
\hline
\end{tabular}




\begin{tabular}{|c|c|c|c|c|c|c|c|c|}
\hline TYR201-Main & POPC468-Side & $11.42 \%$ & VAL131-Main & POPC464-Side & $23.91 \%$ & TYR246-Side & POPC452-Side & $44.87 \%$ \\
\hline TRP385-Side & POPC478-Side & $10.74 \%$ & TYR121-Side & POPC457-Side & $15.45 \%$ & HSD220-Side & POPC571-Side & $21.28 \%$ \\
\hline TYR162-Side & POPC544-Side & $17.17 \%$ & THR203-Side & POPC449-Side & $17.92 \%$ & LYS82-Side & POPC552-Side & $14.37 \%$ \\
\hline TYR246-Side & POPC452-Side & $20.36 \%$ & TYR121-Main & POPC465-Side & $19.72 \%$ & LYS161-Side & POPC584-Side & $14.09 \%$ \\
\hline SER130-Side & POPC494-Side & $12.50 \%$ & ARG358-Side & POPC556-Side & $20.00 \%$ & LYS86-Side & POPC568-Side & $20.80 \%$ \\
\hline LYS411-Side & POPC567-Side & $12.26 \%$ & ARG134-Side & POPC450-Side & $48.18 \%$ & LYS410-Side & POPC569-Side & $24.99 \%$ \\
\hline GLU351-Main & POPC548-Side & $13.69 \%$ & LYS107-Side & POPC451-Side & $32.89 \%$ & ARG163-Side & POPC578-Side & $10.38 \%$ \\
\hline TYR185-Side & POPC468-Side & $11.50 \%$ & CYS164-Main & POPC544-Side & $11.50 \%$ & LYS193-Side & POPC461-Side & $11.94 \%$ \\
\hline LYS271-Side & POPC569-Side & $18.20 \%$ & GLN118-Main & POPC452-Side & $21.24 \%$ & LEU225-Main & POPC574-Side & $16.57 \%$ \\
\hline LYS411-Side & POPC569-Side & $10.62 \%$ & TRP385-Side & POPC451-Side & $31.66 \%$ & TYR165-Side & POPC564-Side & $21.72 \%$ \\
\hline TYR347-Side & POPC560-Side & $16.25 \%$ & TYR160-Side & POPC584-Side & $10.18 \%$ & TYR195-Side & POPC451-Side & $10.86 \%$ \\
\hline ARG163-Side & POPC592-Side & $18.76 \%$ & ARG435-Side & POPC456-Side & $39.32 \%$ & ARG163-Side & POPC564-Side & $23.99 \%$ \\
\hline \multirow[t]{8}{*}{ LYS107-Side } & POPC454-Side & $17.72 \%$ & TYR195-Side & POPC489-Side & $26.51 \%$ & LYS166-Main & POPC548-Side & $10.98 \%$ \\
\hline & & & LYS306-Main & POPC556-Side & $26.63 \%$ & & & \\
\hline & & & LEU225-Main & POPC563-Side & $12.65 \%$ & & & \\
\hline & & & ARG358-Main & POPC577-Side & $28.02 \%$ & & & \\
\hline & & & ARG134-Side & POPC460-Side & $17.25 \%$ & & & \\
\hline & & & CYS269-Main & POPC555-Side & $10.62 \%$ & & & \\
\hline & & & TYR162-Side & POPC570-Side & $12.38 \%$ & & & \\
\hline & & & TYR185-Side & POPC536-Side & $15.97 \%$ & & & \\
\hline
\end{tabular}

Table S5. Effect of mutation on the stability of PS2 predicted by I-Mutant 3.0.

\begin{tabular}{|c|c|c|c|c|c|c|}
\hline \multirow{2}{*}{ Mutant } & \multicolumn{2}{|r|}{ Simulation 1} & \multicolumn{4}{|c|}{\begin{tabular}{l|l} 
Simulation 2 & Simulation 3
\end{tabular}} \\
\hline & RSA & $\Delta \Delta \mathrm{G}(\mathrm{kcal} / \mathrm{mol})$ & RSA & $\Delta \Delta \mathrm{G}(\mathrm{kcal} / \mathrm{mol})$ & RSA & $\Delta \Delta \mathrm{G}(\mathrm{kcal} / \mathrm{mol})$ \\
\hline K82R & 46.7 & 0.11 & 62.2 & 0.22 & 17.5 & -0.31 \\
\hline A85V & 56.3 & -0.04 & 59 & 0.09 & 25.4 & 0.24 \\
\hline $\mathrm{V} 101 \mathrm{M}$ & 31.9 & -1.23 & 28 & -1.31 & 21.5 & -1.33 \\
\hline T122P & 1.4 & -0.75 & 10.8 & -1.13 & 35.3 & -0.53 \\
\hline T122R & 1.4 & -0.41 & 10.8 & -0.83 & 35.3 & -0.22 \\
\hline P123L & 60.6 & -0.18 & 33.8 & -0.33 & 13.4 & -0.15 \\
\hline E126K & 104.2 & -0.36 & 83.6 & -0.46 & 92.7 & -0.2 \\
\hline S130L & 49.5 & 0.06 & 48.6 & 0.13 & 46.1 & 0.13 \\
\hline V139M & 52 & -0.91 & 49.4 & -0.81 & 43.6 & -1.09 \\
\hline N141I & 0.7 & 0.79 & 10.2 & 0.66 & 6.1 & 0.54 \\
\hline N141Y & 0.7 & -0.18 & 10.2 & -0.24 & 6.1 & -0.35 \\
\hline L143H & 52.4 & -2.12 & 52.4 & -1.99 & 48.1 & -2.05 \\
\hline V148I & 54.7 & -0.7 & 42.3 & -0.76 & 57.9 & -0.86 \\
\hline K161R & 38.9 & -0.6 & 79.2 & -0.28 & 44.7 & -0.59 \\
\hline R163H & 81.2 & -1.17 & 65.5 & -1.28 & 72.5 & -1.29 \\
\hline $\mathrm{H} 169 \mathrm{~N}$ & 14.8 & -1.32 & 32.4 & -0.91 & 19.8 & -1.19 \\
\hline M174V & 25 & -0.35 & 37.5 & -0.3 & 52 & -0.2 \\
\hline S175C & 28.2 & -0.66 & 44.4 & -0.61 & 23 & -0.67 \\
\hline G212V & 10.2 & -0.19 & 5.1 & -0.07 & 25.4 & 0 \\
\hline V214L & 64.4 & -0.42 & 46.8 & -0.3 & 63.1 & -0.49 \\
\hline Q228L & 9.5 & 0.12 & 24.1 & 0.23 & 11.2 & 0.02 \\
\hline
\end{tabular}




\begin{tabular}{|c|c|c|c|c|c|c|}
\hline Y231C & 8.4 & -1.31 & 15.9 & -1.26 & 16.4 & -1.11 \\
\hline I235F & 9.2 & -1.13 & 7 & -1.23 & 9.2 & -1.03 \\
\hline A237V & 0 & -0.57 & 0.9 & -0.59 & 1.8 & -0.57 \\
\hline L238F & 0 & -1.37 & 4.9 & -1.36 & 8.2 & -1.32 \\
\hline L238P & 0 & -2.03 & 4.9 & -2.01 & 8.2 & -1.99 \\
\hline M239I & 30 & -0.98 & 18.5 & -0.91 & 34 & -0.89 \\
\hline M239V & 30 & -0.95 & 18.5 & -0.84 & 34 & -0.86 \\
\hline A252T & 3.6 & -0.88 & 1.8 & -1.02 & 1.8 & -1.11 \\
\hline A258T & 0 & -1.6 & 52.6 & -1.06 & 29.9 & -1.36 \\
\hline T301M & 2.9 & -0.37 & 6.5 & -0.33 & 44.7 & -0.23 \\
\hline P334A & 25.4 & -1.31 & 65.5 & -1.28 & 45.8 & -1.18 \\
\hline P334R & 25.4 & -0.87 & 65.5 & -0.95 & 45.8 & -0.91 \\
\hline P348L & 49.3 & -0.19 & 99.4 & -0.5 & 62.7 & -0.23 \\
\hline A377V & 0 & 0.08 & 0.9 & 0.24 & 0.9 & -0.54 \\
\hline V393M & 56.6 & -0.98 & 29.3 & -0.77 & 57.9 & -0.75 \\
\hline T421M & 52.2 & -0.28 & 17.3 & -0.55 & 49 & -0.17 \\
\hline T430M & 40.4 & -0.28 & 43.3 & -0.28 & 12.3 & -0.31 \\
\hline D439A & 72.2 & -0.1 & 55.5 & -0.16 & 43.7 & 0.1 \\
\hline$*$ Red rep & -19 & -19 & $-p 26$ & $4 t$ & \\
\hline
\end{tabular}

* Red represents pathogenic and green represents non-pathogenic mutations.

RSA: Relative solvent accessibility of the mutated site.

Table S6. Assessment of mutation effects on PS2 using MCSM, SDM, and DUET (Pathogenic: Red and Nonpathogenic: Green).

\begin{tabular}{|c|c|c|c|c|c|c|c|c|c|c|c|c|}
\hline \multirow[b]{2}{*}{ Mutation } & \multicolumn{4}{|c|}{ Simulation 1} & \multicolumn{4}{|c|}{ Simulation 2} & \multicolumn{3}{|c|}{ Simulation 3} & \multirow[b]{2}{*}{$\begin{array}{c}\text { DUET } \\
\text { predicted } \\
\Delta \Delta \mathrm{G}\end{array}$} \\
\hline & $\begin{array}{l}\text { RSA } \\
(\%)\end{array}$ & $\begin{array}{c}\text { mCSM } \\
\text { predicted } \\
\Delta \Delta \mathrm{G}\end{array}$ & $\begin{array}{c}\text { SDM } \\
\text { predicted } \\
\Delta \Delta \mathrm{G} \\
\end{array}$ & $\begin{array}{c}\text { DUET } \\
\text { predicted } \\
\Delta \Delta \mathrm{G}\end{array}$ & $\begin{array}{l}\mathrm{RSA} \\
(\%)\end{array}$ & $\begin{array}{c}\text { mCSM } \\
\text { predicted } \\
\Delta \Delta \mathrm{G}\end{array}$ & $\begin{array}{c}\text { SDM } \\
\text { predicted } \\
\Delta \Delta \mathrm{G}\end{array}$ & $\begin{array}{c}\text { DUET } \\
\text { predicted } \\
\Delta \Delta \mathrm{G} \\
\end{array}$ & $\begin{array}{c}\text { RSA } \\
(\%)\end{array}$ & $\begin{array}{c}\text { mCSM } \\
\text { predicted } \\
\Delta \Delta \mathrm{G}\end{array}$ & $\begin{array}{c}\text { SDM } \\
\text { predicted } \\
\Delta \Delta \mathrm{G}\end{array}$ & \\
\hline K82R & 60.9 & -0.282 & -0.01 & -0.012 & 70.4 & -0.163 & 0.05 & 0.117 & 15.4 & -0.79 & -0.79 & -0.675 \\
\hline A85V & 82.2 & -0.279 & -0.12 & 0.033 & 82.6 & -0.271 & -0.12 & -0.043 & 21.3 & -0.241 & -0.12 & -0.068 \\
\hline V101M & 41.1 & -0.488 & 0.16 & -0.21 & 40 & -0.369 & 0.16 & -0.085 & 31 & -0.408 & 0.16 & -0.126 \\
\hline T122P & 2.5 & -0.409 & -1.5 & -0.396 & 13.9 & -0.471 & -0.89 & -0.343 & 50.5 & -0.472 & 0.12 & -0.181 \\
\hline $\mathrm{T} 122 \mathrm{R}$ & 2.5 & -0.225 & -1.09 & -0.298 & 13.9 & -0.357 & -0.64 & -0.293 & 50.5 & -0.286 & -0.87 & -0.302 \\
\hline P123L & 57.7 & -0.286 & 1.88 & 0.412 & 28.2 & -0.288 & -0.58 & -0.097 & 2.3 & -0.631 & -0.78 & -0.511 \\
\hline E126K & 110.6 & 0.575 & -0.04 & 0.892 & 82.8 & 0.573 & -0.16 & 0.87 & 101.3 & 0.675 & -0.04 & 0.988 \\
\hline S130L & 66.4 & -0.229 & 0.12 & -0.046 & 65.7 & -0.158 & 0.12 & 0.028 & 49.7 & -0.204 & 0.04 & -0.041 \\
\hline V139M & 68.4 & -0.342 & 0.16 & -0.057 & 64.5 & -0.359 & 0.16 & -0.075 & 58.6 & -0.37 & 0.16 & -0.086 \\
\hline N141I & 2.1 & -0.486 & 1.21 & 0.164 & 15.1 & 0.045 & 0.29 & 0.44 & 9.9 & 0.318 & -0.32 & 0.538 \\
\hline N141Y & 2.1 & -0.621 & 0.21 & -0.468 & 15.1 & -0.187 & 0.36 & -0.025 & 9.9 & -0.012 & -0.55 & -0.171 \\
\hline L143H & 70 & -0.632 & -0.6 & -0.576 & 70.8 & -0.582 & -0.98 & -0.631 & 66.8 & -0.722 & -0.98 & -0.764 \\
\hline V148I & 73 & -0.535 & 0.35 & -0.056 & 57.6 & -0.571 & 0.35 & -0.094 & 78.4 & -0.474 & 0.35 & 0.008 \\
\hline K161R & 39.8 & -0.418 & 0.43 & 0 & 75.3 & -0.137 & 0.26 & 0.252 & 45.1 & -0.508 & 0.26 & -0.122 \\
\hline R163H & 83.6 & -0.968 & 0.14 & -0.933 & 63.9 & -0.95 & 0.3 & -0.886 & 68.2 & -1.35 & 0.14 & -1.328 \\
\hline $\mathrm{H} 169 \mathrm{~N}$ & 19.4 & -0.989 & -0.58 & -0.933 & 39.9 & -0.905 & -0.58 & -0.85 & 21.9 & -0.566 & -0.92 & -0.571 \\
\hline M174V & 32.9 & -1.282 & -0.15 & -0.836 & 47.1 & -0.977 & -0.15 & -0.508 & 65.7 & -0.858 & -0.15 & -0.381 \\
\hline S175C & 36.3 & -0.153 & 1.01 & 0.37 & 56.8 & -0.187 & 0.5 & 0.213 & 34.5 & -0.211 & 0.5 & 0.189 \\
\hline G212V & 19.5 & 0.601 & 0.72 & 1.16 & 6.5 & 0.582 & -0.75 & 0.834 & 52.1 & 0.196 & 0.72 & 0.771 \\
\hline
\end{tabular}




\begin{tabular}{|c|c|c|c|c|c|c|c|c|c|c|c|c|}
\hline V214L & 85.5 & -0.301 & 0.68 & 0.263 & 63.2 & -0.3 & 0.68 & 0.264 & 83.4 & -0.241 & 0.68 & 0.325 \\
\hline Q228L & 9.5 & 0.47 & 0.34 & 0.886 & 26.6 & 0.508 & -0.23 & 0.779 & 12.1 & 0.576 & 0.34 & 0.988 \\
\hline $\mathrm{Y} 231 \mathrm{C}$ & 9.6 & -1.544 & -1.55 & -1.589 & 17.4 & -0.945 & -0.74 & -0.816 & 19.6 & -1.137 & -0.28 & -0.929 \\
\hline I235F & 11.2 & -1.741 & -0.82 & -1.805 & 8.5 & -1.44 & -0.86 & -1.534 & 11.4 & -1.417 & -0.86 & -1.513 \\
\hline $\mathrm{A} 237 \mathrm{~V}$ & 0 & -0.885 & -1.14 & -0.813 & 1.6 & -0.789 & -0.85 & -0.632 & 2.3 & -0.466 & -0.85 & -0.281 \\
\hline $\mathrm{L} 238 \mathrm{~F}$ & 0.2 & -1.655 & -1.31 & -1.886 & 6.4 & -1.402 & -1.18 & -1.604 & 11.6 & -1.433 & -1.14 & -1.621 \\
\hline L238P & 0.2 & -1.442 & -4.14 & -2.088 & 6.4 & -1.186 & -4.31 & -1.851 & 11.6 & -1.227 & -2.75 & -1.588 \\
\hline M239I & 38.2 & -1.073 & 0.11 & -0.546 & 20.6 & -1.049 & 0.11 & -0.52 & 39.7 & -1.053 & 0.11 & -0.524 \\
\hline M239V & 38.2 & -1.452 & -0.15 & -1.019 & 20.6 & -1.474 & -0.15 & -1.042 & 39.7 & -1.406 & -0.15 & -0.969 \\
\hline A252T & 1.5 & -1.518 & -2.85 & -1.735 & 1 & -1.264 & -2.82 & -1.462 & 2 & -0.878 & -2.82 & -1.056 \\
\hline A258T & 0 & -1.707 & -3.21 & -1.993 & 69.1 & -0.757 & -1.53 & -0.665 & 33.3 & -0.89 & -1.53 & -0.807 \\
\hline T301M & 3 & -0.202 & -0.68 & -0.398 & 8.8 & -0.27 & -0.47 & -0.332 & 24.3 & -0.752 & 0.58 & -0.531 \\
\hline P334A & 29.2 & -0.582 & -0.36 & -0.343 & 69.5 & -0.442 & -0.36 & -0.194 & 46.5 & -1.055 & 1.51 & -0.307 \\
\hline P334R & 29.2 & -0.011 & -0.67 & 0.132 & 69.5 & -0.03 & -0.67 & 0.114 & 46.5 & -0.262 & 1.77 & 0.322 \\
\hline P348L & 58.3 & -0.258 & -0.58 & -0.065 & 94.8 & -0.507 & 0.78 & -0.004 & 75.8 & -0.382 & -0.58 & -0.182 \\
\hline A377V & 0 & -0.404 & -1.14 & -0.288 & 0.2 & -0.396 & -0.85 & -0.205 & 0.6 & -0.632 & -0.84 & -0.458 \\
\hline V393M & 77.8 & -0.343 & 0.16 & -0.058 & 40.1 & 0.036 & 0.16 & 0.334 & 81.4 & -0.307 & 0.16 & -0.02 \\
\hline $\mathrm{T} 421 \mathrm{M}$ & 71.5 & -0.059 & 1.19 & 0.42 & 23.2 & -0.034 & 0.47 & 0.263 & 60.8 & -0.041 & 1.19 & 0.438 \\
\hline T430M & 47 & 0.158 & 1.19 & 0.631 & 55 & 0.161 & 1.19 & 0.634 & 11.3 & 0.25 & 0.55 & 0.568 \\
\hline D439A & 84.3 & -0.329 & 1.41 & 0.313 & 64.2 & -0.61 & 1.48 & 0.047 & 47.1 & 0.244 & 1.24 & 0.84 \\
\hline
\end{tabular}



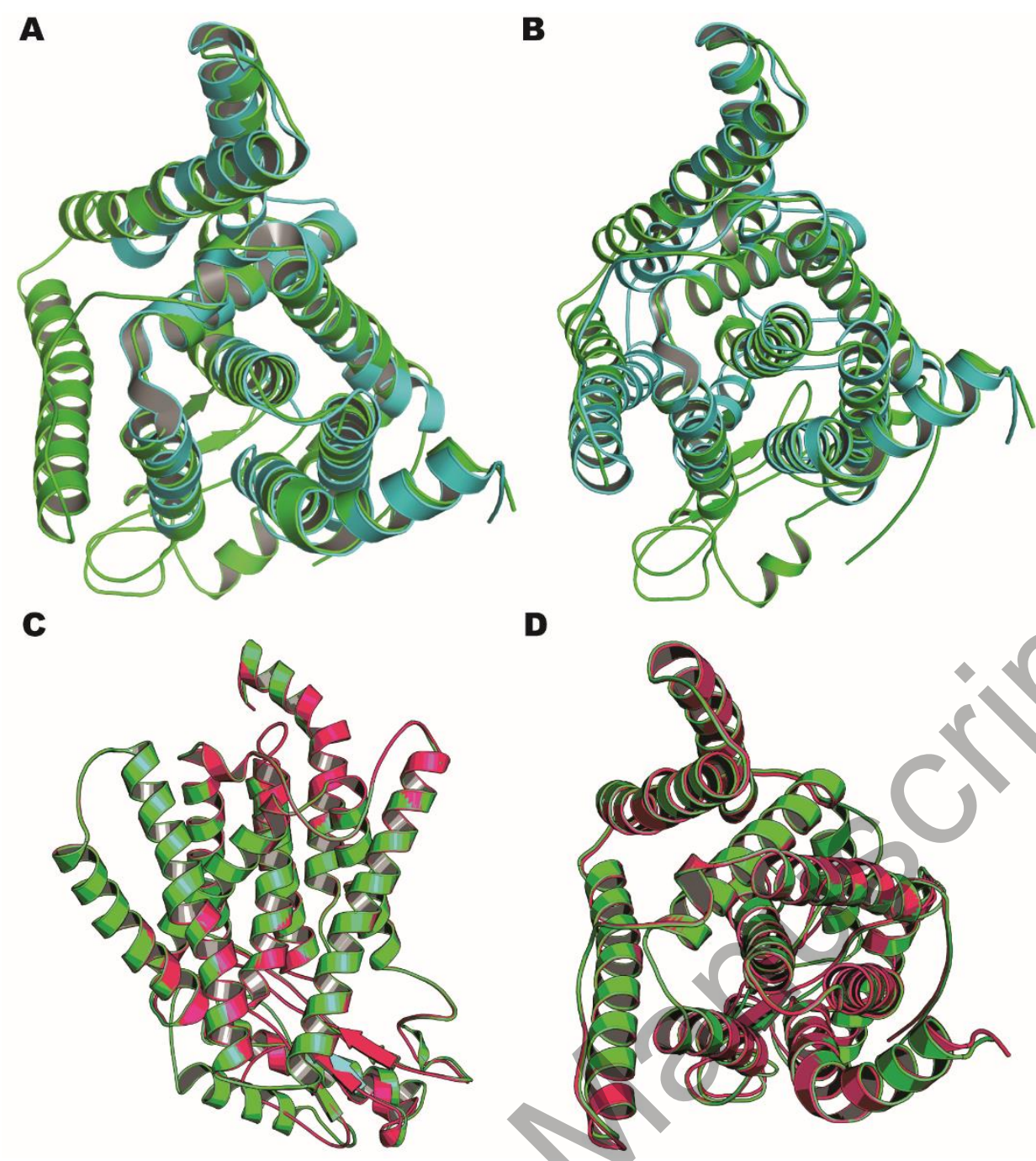

D

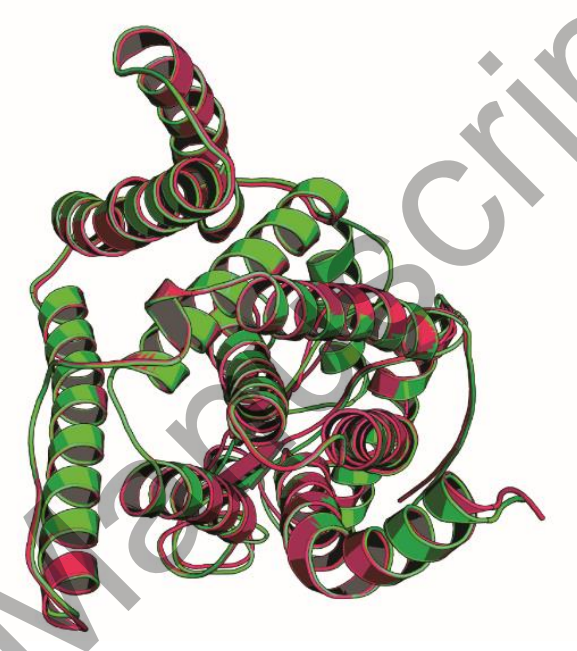

Figure S1. (A) Structural superimposition of modeled PS2 (green) with PS1 from cryo-EM structure 5A63 (cyan). (B) Structural superposition of homology modeled PS2 (green) and the cryo-EM structure 5FN2 (cyan). (C) Structural superposition of homology modeled PS2 (pink) and the complete homology model of PS1 developed by us (lime green). (D) Top view of the structural superimposed homology models of PS1 and PS2. The intracellular large hydrophilic loop harbors two important beta-strands in PS2, whereas PS1 holds three strands. The images were generated using PyMOL. 

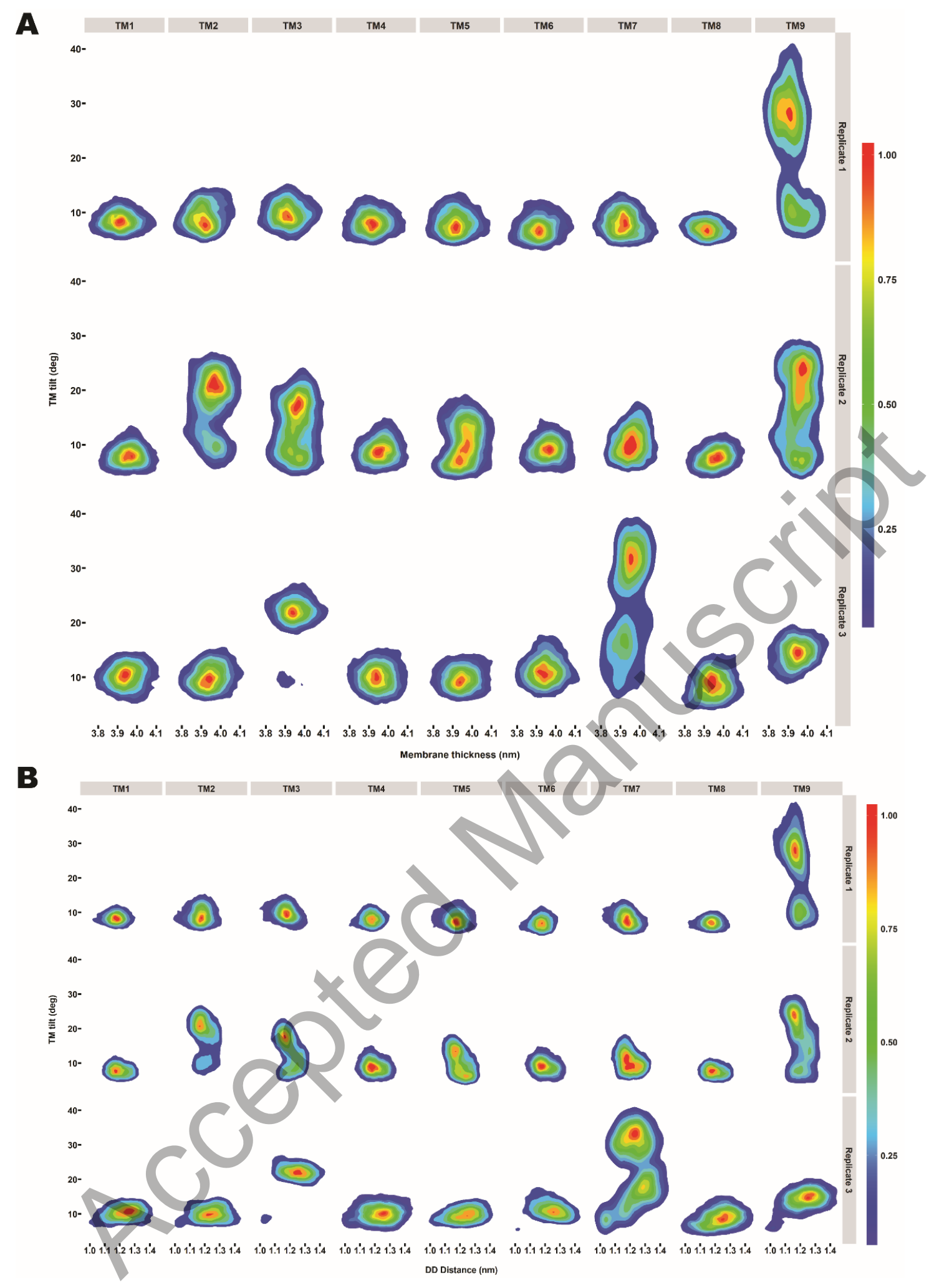

Figure S2. (A) The simulated distributions of TMs projected onto the membrane thickness and tilt angle of TMs in PS2. (B) The simulated distributions of TMs projected onto the Asp263-Asp366 distance and tilt angles of TMs. The last $300 \mathrm{~ns}$ of three seeds were used for calculation. 
A
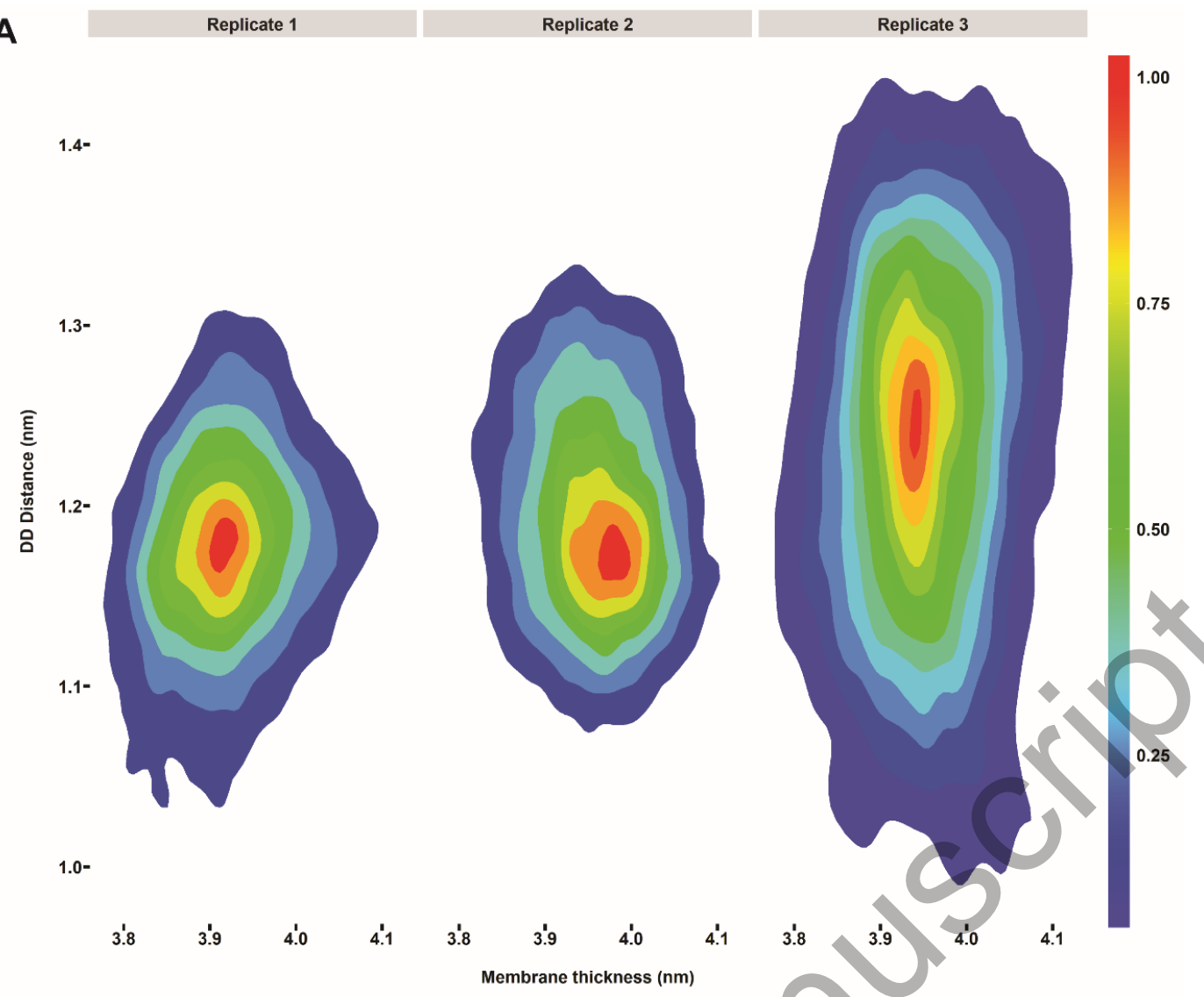

$1.0-$
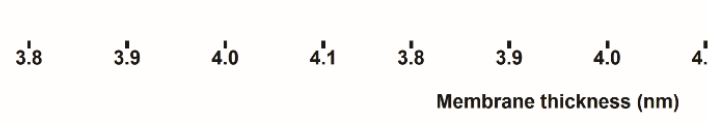

B
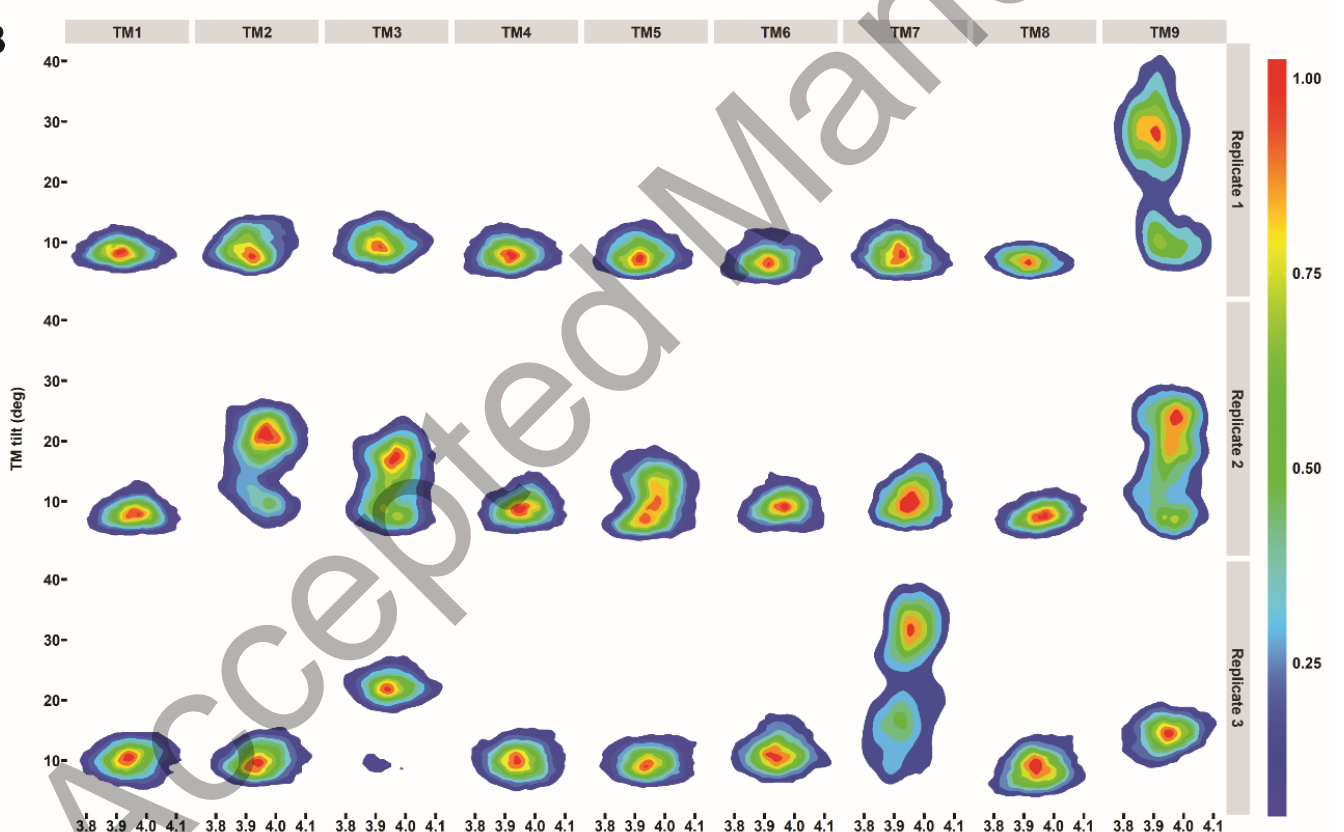

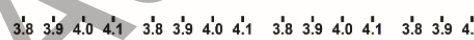
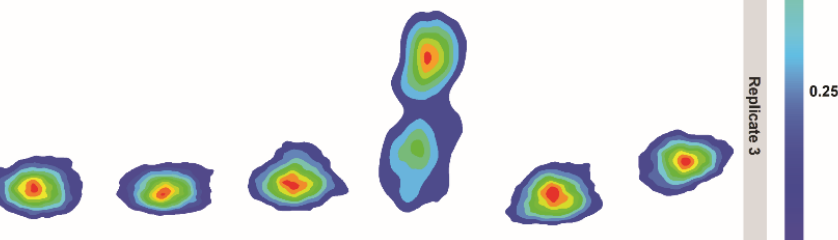

Membrane thickness $(\mathrm{nm})$

Figure S3. (A) Simulated distributions of membrane thickness with respect to Asp-Asp distance in PS2. (B) Simulated distributions of TMs projected onto membrane thickness and tilt angle over the last $300 \mathrm{~ns}$ of PS2. 
A

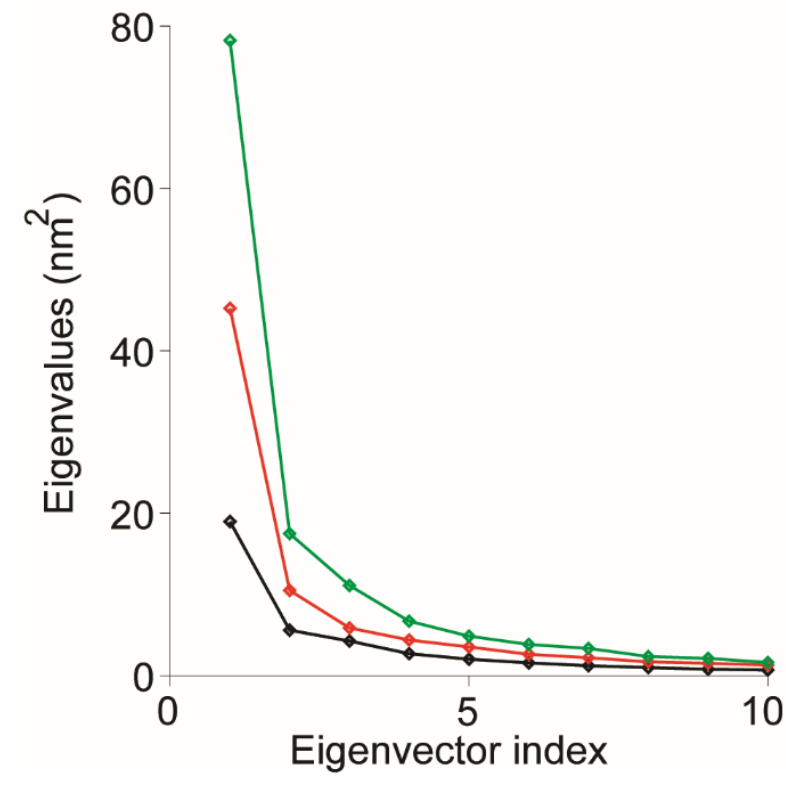

B

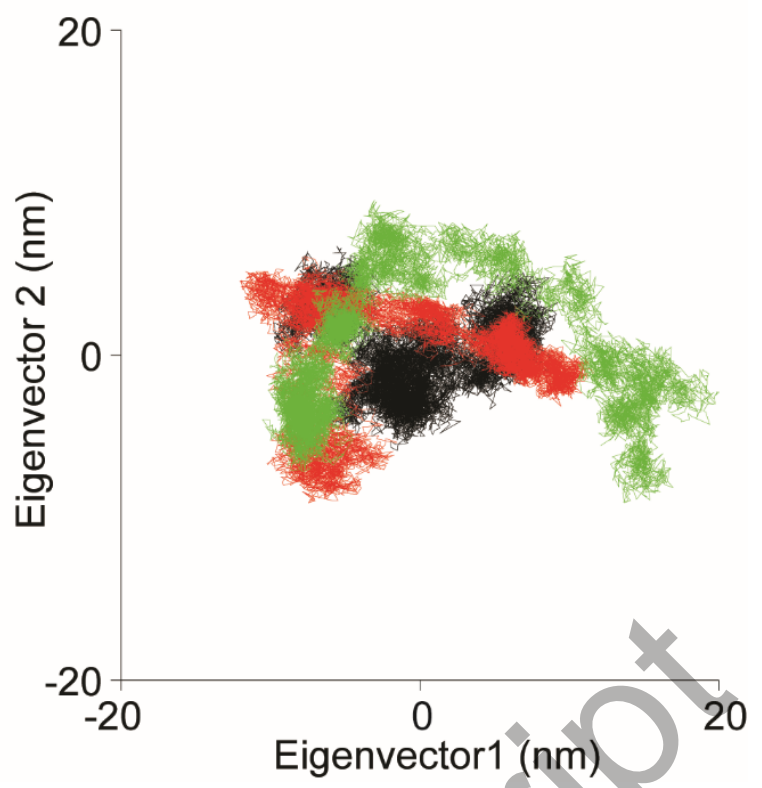

Figure S4. PCA from the last 300 ns trajectory of the three independent simulations of PS2 in pure POPC lipid bilayer. (A) The movement of main-chain atoms of PS2 on the basis of eigenvalues. (B) The 2dimesional projection of movements along the EV1 and EV2 in phase space (Black: System 1, Red: System 2 and Green: System 3).

A

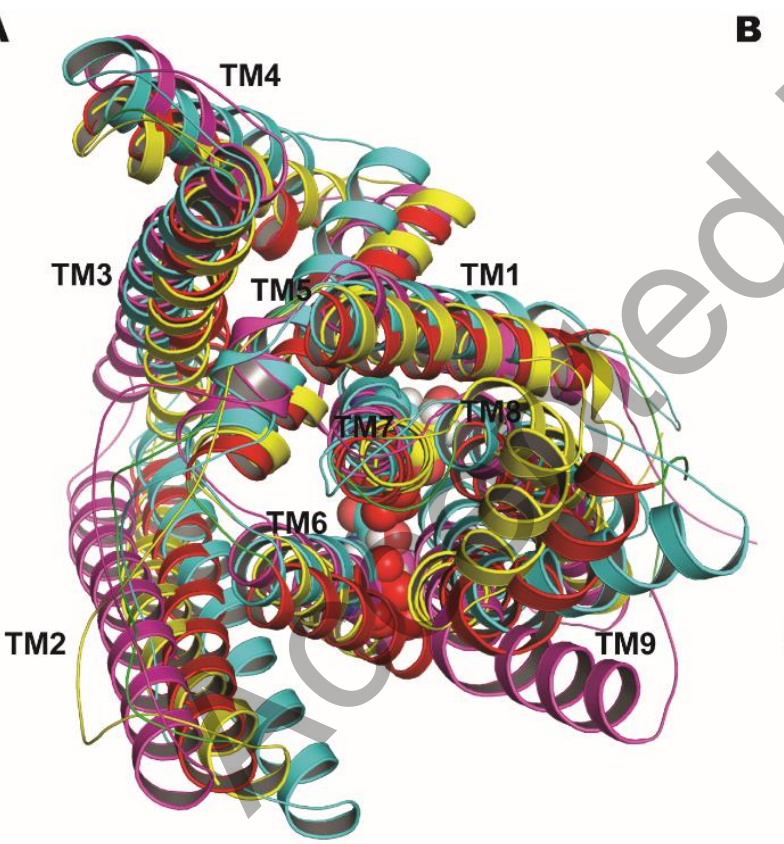

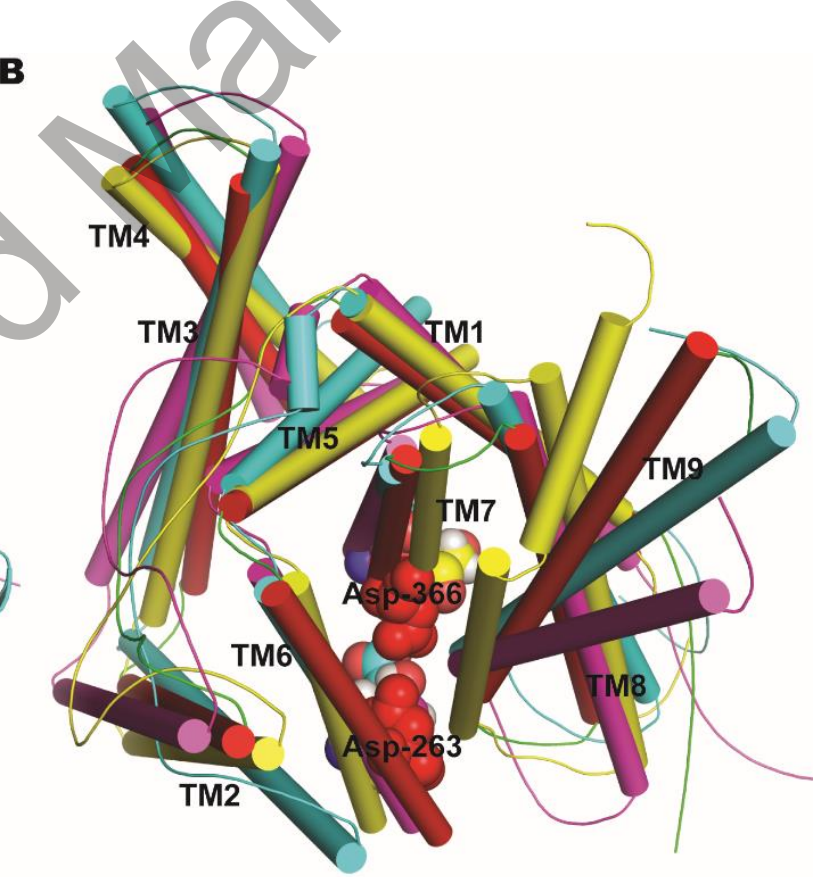

Figure S5. (A) The solid ribbon view of the superimposition of modeled PS2 before MD (cyan) with the cluster representative of PS2 (obtained after MD). (B) The helical structural superposition of homologymodeled PS2 (cyan) and the cluster representative structures of PS2 (Red: System 1, Magenta: System 2 
and Yellow: System 3). The catalytic residues are shown in spheres. The images were generated using PyMOL.
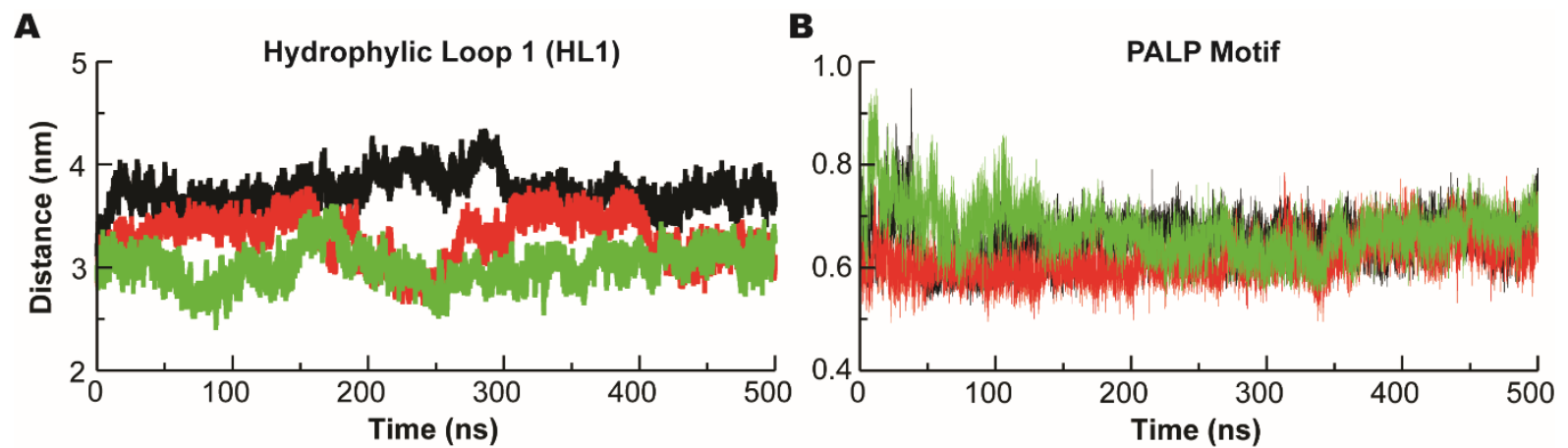

Figure S6. The average C $\alpha$-distance profile of the hydrophilic loop 1 (HL1) of PS2 during 500 ns MD simulation. (B) The average C $\alpha$-distance profile of the PALP motif of PS2 during MD simulation (Black: Simulation 1, Red: Simulation 2 and Green: Simulation 3).

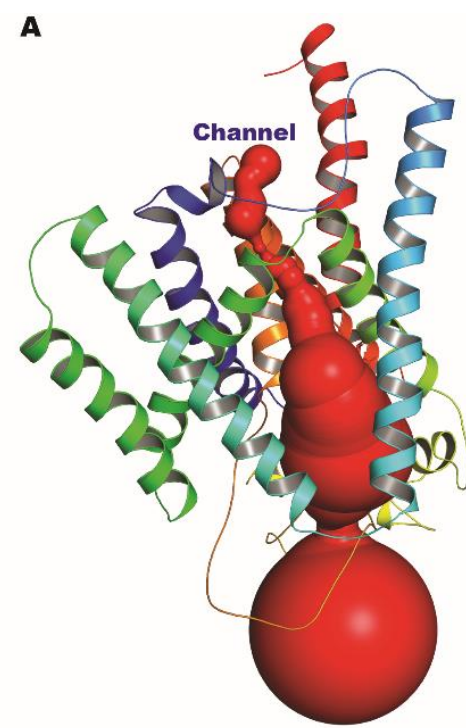

B

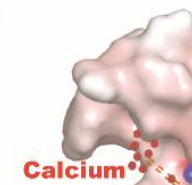

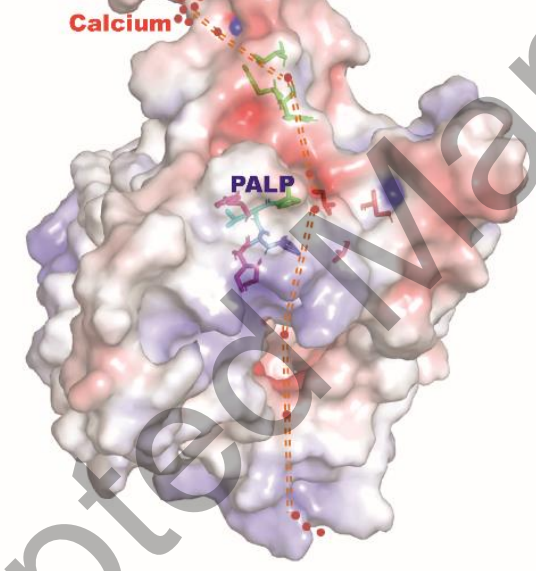

c

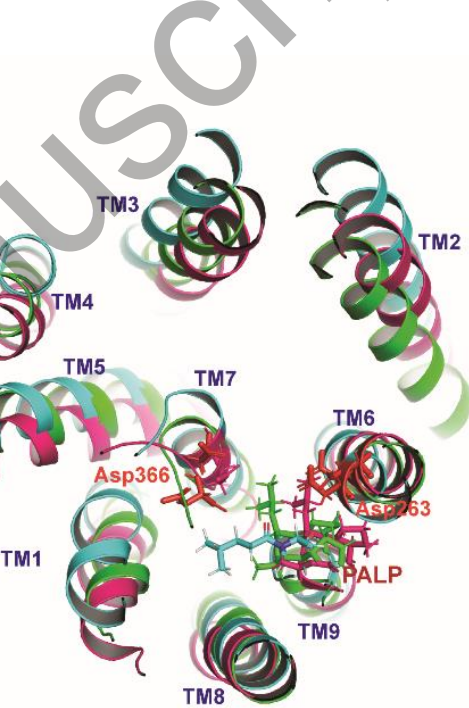

Figure S7. The proposed ion conductance channel displaying the plausible calcium leakage route in PS2, based on the structural superposition with PS1 channel. (A) The computed channel of PS2 obtained using MOLEonline web server where only the representative structure of simulation 2 displayed this channel.

(B) The electrostatic surface representation of PS2, displaying the probable route dispensable for $\mathrm{Ca}^{2+}$ leak activity. The probable root proposed is based available literature on PS1. The amino acid residues of TM6, TM7, TM8 and TM9 involved in this pathway have been shown in stick representation. (C) The top view of close and open conformation of PALP motif forming the channel pore in the three representative structures of PS2 obtained from clustering (Green: Simulation 1, Cyan: Simulation 2 and Magenta: Simulation 3). 

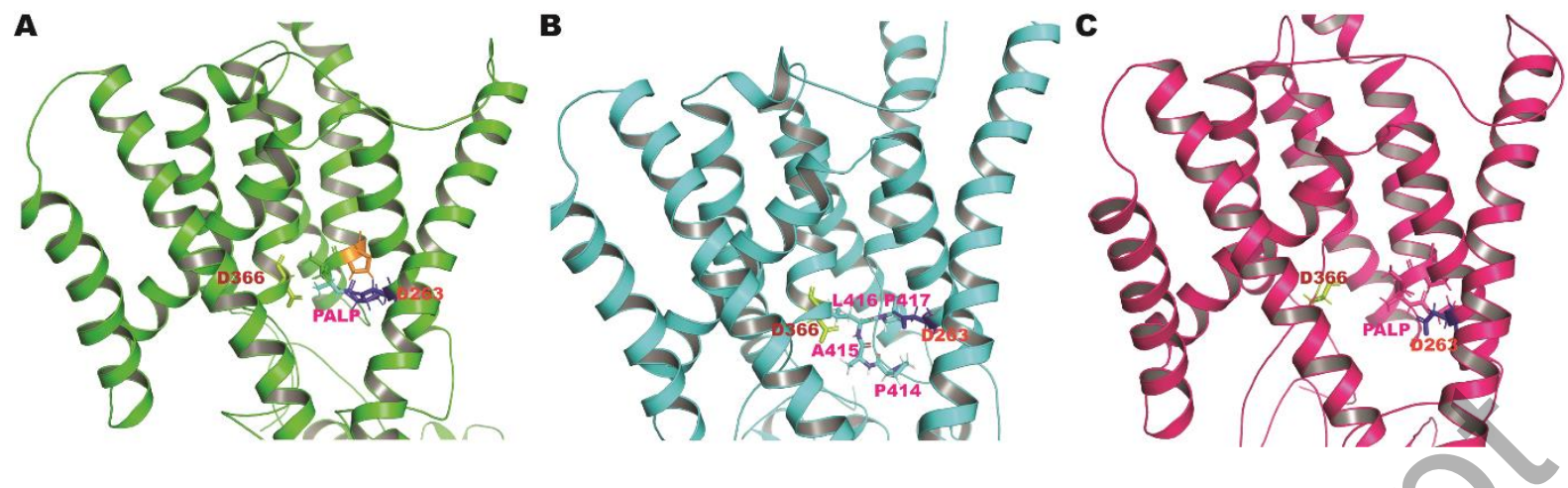

Figure S8. The orientation of catalytic aspartates and PALP motif (shown in stick representation) in PS2 obtained from cluster representative of the three seeded simulation. (A) Cluster-representative structure from simulation 1; (B) Cluster-representative structure from simulation 1; (C) Cluster-representative structure from simulation 3 .
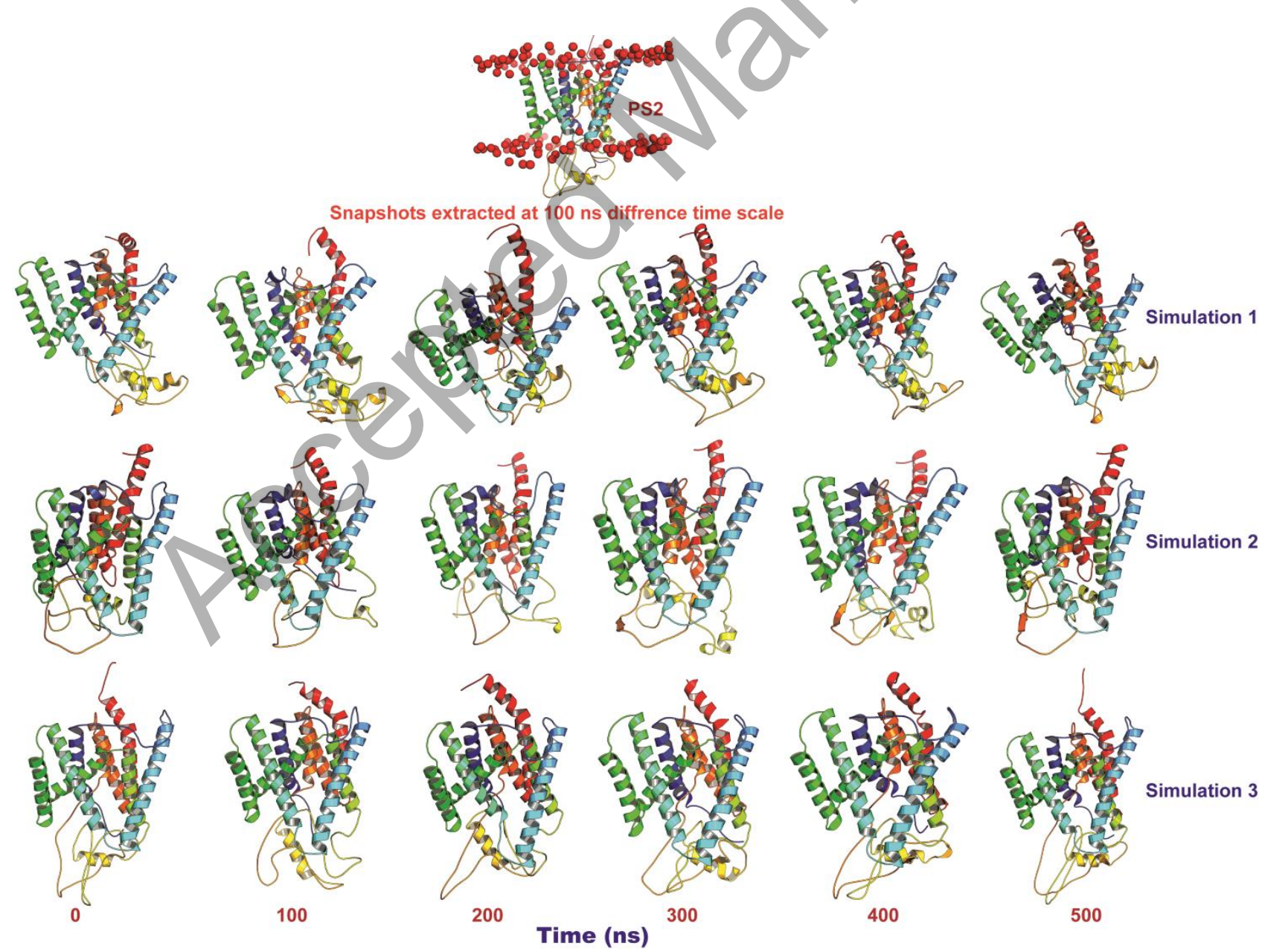

400 
Figure S9. Solid ribbon representation of PS2 structures extracted from MD trajectories at different times from the three independent 500-ns simulations.
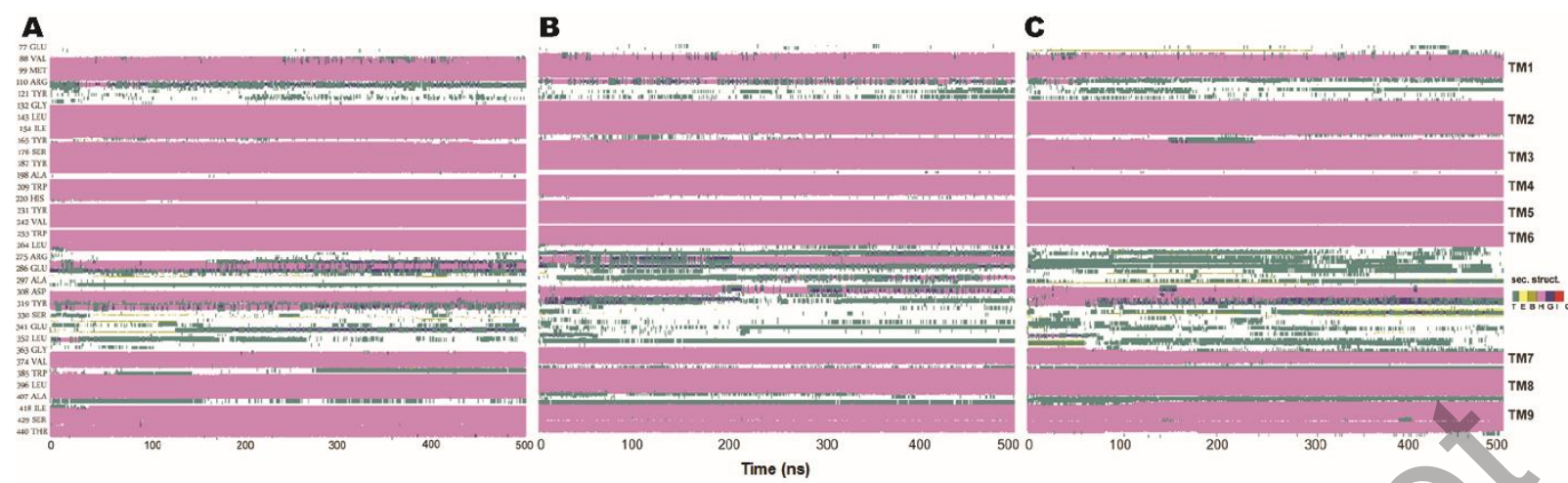

Figure S10. Evolution of secondary structure elements of PS2 over the time scale of 500 ns of MD. (A) Simulation 1. (B) Simulation 2. (C) Simulation 3. Purple color represents helix structure, which is interestingly seen to a variable extent also in the large HL2, consistent with a helical motif being autocleaved during maturation of this loop.

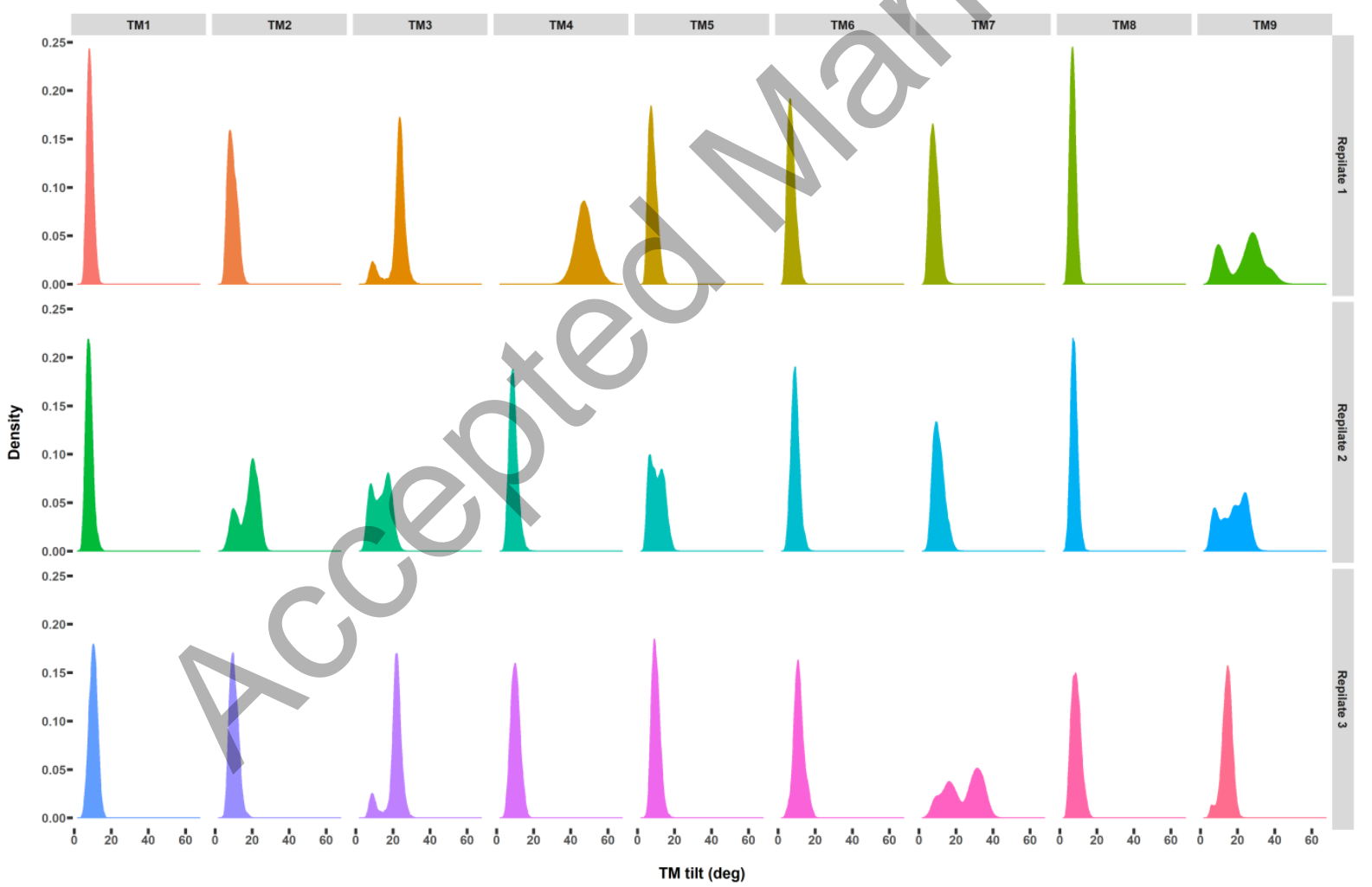

Figure S11. Distribution of tilt angles for TM helices of PS2 (during the last $300 \mathrm{~ns}$ time) computed using gmx helixorient program of GROMACS. 


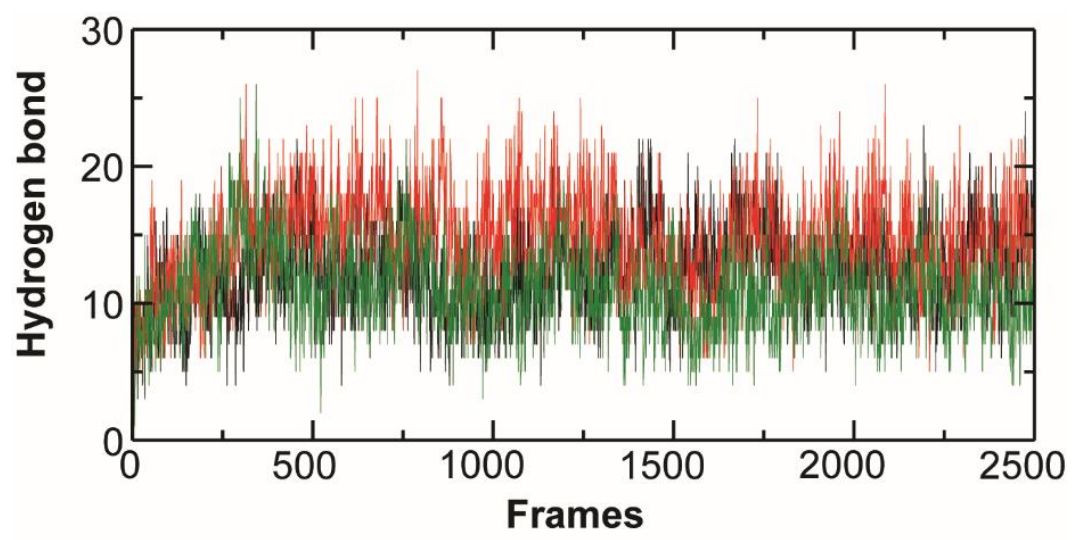

Figure S12. Number of hydrogen bonds formed between lipids (POPC) and PS2 during all-atom MD simulation in the lipid bilayer (Black: Simulation 1, Red: Simulation 2 and Green: Simulation 3). 